\title{
Plant gross primary production, plant respiration and carbonyl sulfide emissions over the globe inferred by atmospheric inverse modelling
}

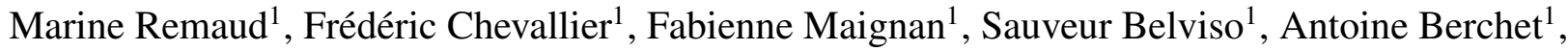 \\ Alexandra Parouffe ${ }^{1}$, Camille Abadie $^{1}$, Cédric Bacour ${ }^{1}$, Sinikka Lennartz $^{2}$, and Philippe Peylin ${ }^{1}$ \\ ${ }^{1}$ Laboratoire des Sciences du Climat et de l'Environnement, CEA-CNRS-UVSQ, UMR8212, IPSL, Saint-Aubin,France \\ ${ }^{2}$ Institute and Chemistry and Biology of the Marine Environment, University of Oldenburg, Oldenburg, Germany
}

Correspondence: Marine Remaud (mremaud@1sce.ipsl.fr)

\begin{abstract}
Carbonyl Sulphide (COS), a trace gas showing striking similarity to $\mathrm{CO}_{2}$ in terms of biochemical diffusion pathway into leaves, has been recognized as a promising indicator of the plant gross primary production (GPP), the amount of carbon dioxide that is absorbed through photosynthesis by terrestrial ecosystems. However, large uncertainties about the other components of its atmospheric budget prevent us from directly relating the atmospheric COS measurements to GPP. The largest uncertainty comes from the closure of its atmospheric budget, with a source component missing. Here, we explore the benefit of assimilating both $\mathrm{COS}$ and $\mathrm{CO}_{2}$ measurements into the $\mathrm{LMDz}$ atmospheric transport model to obtain consistent information on GPP, plant respiration and COS budget. To this end, we develop an analytical inverse system that optimizes biospheric fluxes for the 15 plant functional types (PFTs) defined in the ORCHIDEE global land surface model. Plant uptake of COS is parameterized as a linear function of GPP and of the leaf relative uptake (LRU), which is the ratio of $\mathrm{COS}_{\text {to }} \mathrm{CO}_{2}$ deposition

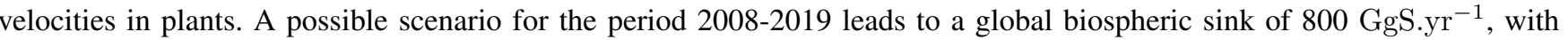
higher absorption in the high latitudes and higher oceanic emissions between 400 and $600 \mathrm{GgS}_{\mathrm{yr}}{ }^{-1}$ most of which is located in the tropics. As for the $\mathrm{CO}_{2}$ budget, the inverse system increases GPP in the high latitudes by a few GtC.yr ${ }^{-1}$ without modifying the respiration compared to the ORCHIDEE fluxes used as a prior. In contrast, in the tropics the system tends to weaken both respiration and GPP. The optimized components of the $\mathrm{COS}$ and $\mathrm{CO}_{2}$ have been evaluated against independent measurements over Northern America, the Pacific Ocean, at three sites in Japan and at one site in France. Overall, the posterior COS concentrations are in better agreement with the COS retrievals at $250 \mathrm{hPa}$ from the MIPAS satellite and with airborne measurements made over North America and the Pacific Ocean. The system seems to have rightly corrected the underestimated GPP over the high latitudes. However, the change in seasonality of GPP in the tropics disagrees with Solar Induced Fluorescence (SIF) data. The decline in biospheric sink in the Amazon driven by the inversion also disagrees with MIPAS COS retrievals at $250 \mathrm{hPa}$, highlighting the lack of observational constraints in this region. Moreover, the comparison with the surface measurements in Japan and France suggests misplaced sources in the prior anthropogenic inventory, emphasizing the need for an improved inventory to better partition oceanic and continental sources in Asia and Europe.
\end{abstract}




\section{Introduction}

Globally, the amount of carbon assimilated by plant photosynthesis, known as Gross Primary Productivity (GPP), exceeds plant respiration by a few GtC.yr ${ }^{-1}$, which allows terrestrial ecosystems to be a global sink for $\mathrm{CO}_{2}$ in the atmosphere. By absorbing a quarter of the atmospheric carbon dioxide $\left(\mathrm{CO}_{2}\right)$ emitted by human activities, terrestrial ecosystems help to mitigate the increasing $\mathrm{CO}_{2}$ concentration in the atmosphere, the main driver of climate change (Friedlingstein et al., 2020). The spatial distribution of this carbon sink remains uncertain and a subject of intensive research. This is obviously also the case for its components, GPP and respiration, and for those gross fluxes, the uncertainty on the seasonal variations and the overall magnitude are also very large (Anav et al., 2015).

The two most common methods for estimating ecosystem-wide GPP and respiration are based on eddy-covariance measurements or land surface models (LSMs). While eddy-covariance measurements, on one hand, can be used to routinely estimate GPP and respiration at local scale, their extrapolation to a whole biome is not straightforward due to their small footprint (Jung et al., 2020). Land Surface Models (LSMs), on the other hand, have global coverage but represent processes that are not well described and are therefore heavily tuned (Kuppel et al., 2012). For instance, they disagree on the representation of the large spatial and temporal variability of the $\mathrm{CO}_{2}$ gross and net fluxes (Anav et al., 2015). Satellite retrievals of, e.g., solar-induced fluorescence (SIF) or normalized difference vegetation index (NDVI) (Joiner et al., 2016) are also used to constrain GPP. However, remote sensing methods rely on a number of assumptions to convert satellite-measured photons to on-the-ground photosynthesis (Sun et al., 2018). Therefore, there is a need for new information about GPP or respiration to ensure a better partitioning between the components of the $\mathrm{CO}_{2}$ atmospheric budget.

Carbonyl sulfide (COS) is recognized as a promising tracer of GPP at the leaf scale (Stimler et al., 2010; Seibt et al., 2010) and at large scale (Campbell et al., 2008; Blake et al., 2008). COS follows the same diffusion pathway from the leaf boundary layer to the plant cells where photosynthesis takes place. However, while $\mathrm{CO}_{2}$ is re-emitted into the atmosphere through respiration, COS is nearly irreversibly hydrolized in a reaction catalyzed by the enzyme carbonic anhydrase (CA) (Protoschill-Krebs et al., 1996). Therefore, the atmospheric drawdown of COS reflects the uptake of COS by the plant to a large extent. Despite this property, COS measurements cannot easily be used in inverse modelling to constrain GPP because the other terms of the COS atmospheric budget are also poorly quantified, to the point that the bottom-up COS atmospheric budget is even less closed than the bottom-up $\mathrm{CO}_{2}$ atmospheric budget. The process description of all components of the COS budget (i.e. bottom-up budget) suggests a decreasing concentration of COS, but the latter has been relatively stable around 500 parts per trillion (ppt, 1 ppt is $10^{-12}$ mol.mol ${ }^{-1}$ ) over the past 30 years (Whelan et al., 2018). The current notion is that there is a "missing" source in the current atmospheric COS budget, likely in the tropics (Montzka et al., 2007; Glatthor et al., 2015).

The terrestrial sink induced by both plants and soils has been estimated between 500-1200 GgS.yr ${ }^{-1}$ consistent with the large COS deficit seen in airborne profiles in the northern hemisphere (Campbell et al., 2008; Suntharalingam et al., 2008; Berry et al., 2013a). Soil uptake, resulting from the presence of CA in soil microorganisms, is thought to be much smaller in magnitude than vegetation fluxes (Whelan et al., 2018). In the atmosphere, COS has also two chemical sinks: models indicate

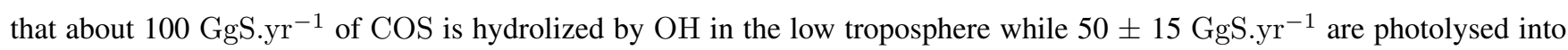


the stratosphere (Whelan et al., 2018). The largest sources of COS are from human activities and the ocean, with minor contributions from biomass burning (50-100 GgS.yr ${ }^{-1}$, Glatthor et al. (2017); Stinecipher et al. (2019)). The oceanic source has been estimated between 200 and $400{\mathrm{GgS} . \mathrm{yr}^{-1}}^{-1}$ (Lennartz et al., 2017, 2020a). The missing source is unlikely to arise from direct ocean emissions since the ship cruises have recorded a sub-saturation of tropical sea waters with respect to COS (Lennartz et al., 2017). COS production from atmospheric oxidation of dimethyl sulfide (DMS) and carbon disulfide $\left(\mathrm{CS}_{2}\right)$ are two other candidates that may support the missing source, as they have been reported to peak over the tropics. Recently, Lennartz et al. (2020a) developed a mechanistic model to simulate $\mathrm{COS}$ emissions via $\mathrm{CS}_{2}$ and estimated a global source of $70 \mathrm{GgS}_{\mathrm{yr}}{ }^{-1}$, too low to support the missing source. However, this model still relies on many assumptions and has limitations such as the lack of oceanic horizontal transport. As for the emissions through DMS, the oxidation yield is currently deduced from experiments carried out under conditions which are not representative of the atmospheric environment with high DMS concentrations and without $N O x$ at $298 \mathrm{~K}$ (Barnes et al., 1996). The recent identification of novel DMS oxidation products (Berndt et al., 2019; Veres et al., 2020) could challenge our current understanding of the mechanistic links between DMS and COS formation into the atmosphere. Regarding the anthropogenic emissions, the inventory from Kettle et al. (2002) used by most top-down studies leading to a high oceanic source has been demonstrated to be incomplete (Blake et al., 2004; Du et al., 2016). The anthropogenic inventory has been revised upward from $200 \mathrm{GgS}_{\mathrm{yr}}{ }^{-1}$ to $400 \mathrm{GgS}_{\mathrm{yr}}{ }^{-1}$, with the largest source shifting from North America to Asia (Zumkehr et al., 2018). Yet, firn air sampled in Antartica and Groenland suggests that anthropogenic emissions are still underestimated and are closer to $600 \mathrm{GgS}_{\mathrm{yr}}{ }^{-1}$ (Aydin et al., 2020).

As an alternative to modelling direct emissions, attempts have been made to constrain the COS budget through inverse or "top-down" approaches. With the help of a transport model and a priori information, these approaches adjust the surface fluxes to better match simulated atmospheric concentrations with observations. Previous top-down assessments of the COS budget identified the missing source as likely being from the ocean, with a total oceanic release between 500 and 1000 GgS.yr ${ }^{-1}$ (Suntharalingam et al., 2008; Berry et al., 2013a; Kuai et al., 2015a; Launois et al., 2015b). This finding is consistent with the high concentrations of COS observed over tropical waters (Montzka et al., 2007; Glatthor et al., 2015; Kuai et al., 2015a), but remains preliminary due to the scarcity of observations (Ma et al., 2021). Top-down approaches have so far followed two computational strategies: the analytical strategy directly computes the closed-form solution to the inverse problem and is in principle reserved for small inverse problems, while the variational strategy can tackle larger problems by iteratively reaching the neighborhood of the closed-form solution. The analytical inverse system used by Berry et al. (2013a) calibrated a single scaling factor for the oceanic source per latitudinal band. Launois et al. (2015b) used a similar technique but they optimized each term of the COS budget at an annual scale from COS surface measurements, applying one scaling factor per COS component. When assimilating Tropospheric Emissions Spectrometer (TES) satellite retrievals, Kuai et al. (2015a) divided the tropics into several regions and optimized one scaling coefficient of the oceanic source per region. Recently, Ma et al. (2021) used a variational inverse system to optimize the COS surface fluxes at each pixel of their model grid using COS surface measurements, but still had to apply a large auto-correlation length to compensate for the sparse observation network. These systems have assimilated only COS atmospheric measurements. 
Here, we present an update of the Launois et al. (2015b) analytical system using recent prior fluxes and many more degrees of freedom given to the inversion. The new system makes it possible to optimize each process by region and by month and in particular, the GPP for each of the 15 Plant Functional Types (PFT) of the ORCHIDEE (ORganizing Carbon and Hydrology In Dynamic Ecosystems, Krinner et al. (2005)) terrestrial model. We assume a linear relationship between GPP and biospheric COS uptake under a leaf relative uptake (LRU) approach. We also take advantage of the additional sophistication of the inversion system to assimilate COS measurements together with $\mathrm{CO}_{2}$ measurements, in order to constrain both GPP and respiration fluxes. Our study period spans 12 years, from 2008 to 2019.

The objectives of our study are threefold:

1. Evaluating the analytical inverse system applied for the first time to the joint assimilation of $\mathrm{COS}$ and $\mathrm{CO}_{2}$ measurements from a technical point of view,

2. Providing an improved COS budget estimate,

3. Providing improved estimates of GPP and respiration based on the joint assimilation of $\mathrm{COS}$ and $\mathrm{CO}_{2}$ measurements.

After a description of the inverse system and its setup in Section 2, inverse results will be shown in Section 3 with an emphasis on the global budget and on the seasonal cycle of the optimized fluxes. In Section 4, the fluxes will be prescribed to the LMDz atmospheric transport model and the resulting concentrations will be evaluated against independent observations over North America, the Pacific Ocean, Japan and France. We will also compare the simulated concentrations against Michelson Interferometer for Passive Atmospheric Sounding (MIPAS) (Fischer et al., 2008) retrievals over the tropics. Finally, we will discuss the potential and limitations of this inverse system to constrain the GPP with COS observations.

\section{Data and method}

\subsection{Atmospheric transport}

We simulate the global atmospheric transport at spatial resolution $3.75^{\circ} \times 1.9^{\circ}$ (longitude times latitude) with 39 layers in the vertical, based on the general circulation model of the Laboratoire de Météorologie Dynamique, LMDz (Hourdin et al., 2020). LMDz6A is our reference version: it was prepared for the $6^{\text {th }}$ Climate Intercomparison Project (CMIP6) as part of the Institut Pierre-Simon Laplace Earth system model. Remaud et al. (2018) evaluated more specifically the skill of the model to represent the transport of passive tracers. We use the offline version of the LMDz code, which was created by Hourdin and Armengaud (1999) and adapted by Chevallier et al. (2005) for atmospheric inversion. It is driven by air mass fluxes calculated by the complete general circulation model, run at the same resolution and nudged here towards winds from the fifth generation of meteorological analyses of the European Centre for Medium-Range Weather Forecasts (ERA5). The off-line model only solves the mass balance equation for tracers, which significantly reduces the computation time.

For the sake of simplicity, we refer to LMDz as the offline model in the following. LMDz is weakly non-linear with respect to the surface fluxes, following the use of slope limiters in the Van Leer (1977) advection scheme which ensures monotonicity. 
Analytical versions of the LMDz tangent-linear and adjoint operators have been developed. Those codes respectively perform operations $\mathbf{M x}$ and $\mathbf{M}^{T} \mathbf{y}^{*}$, with $\mathbf{M}$ the Jacobian matrix of LMDz, $\mathbf{x}$ a vector of input variables of LMDz (i.e. tracer surface fluxes and initial tracer values), and $\mathbf{y}^{*}$ a vector of size the number of output variables (i.e. the atmospheric concentrations at observation location and time), at the machine epsilon despite conditional statements in the LMDz code.

In our study, we assimilate LMDz to one of its Jacobian matrices: we linearized LMDz beforehand around a top-down estimation of the $\mathrm{CO}_{2}$ surface fluxes from the Copernicus Atmosphere Monitoring Service (https://atmosphere.copernicus.eu/). We checked that this linearization using $\mathrm{CO}_{2}$ was still valid for COS fluxes and expected COS flux increment patterns (not shown). The archived Jacobian matrix was generated by the adjoint code of LMDz. This way of doing is in principle an improvement over previous COS studies with LMDz (Launois et al., 2015b; Peylin et al., 2016) which used a rough approximation of the adjoint, called "retro-transport", in which the direction of time was simply reversed in LMDz without strict inversion of the order of calculations (Hourdin and Talagrand, 2006). In addition, we use a much more recent version of LMDz here (LMDz6A, Remaud et al. (2018), vs. LMDz3, Hourdin et al. (2006)), and at higher resolution, in particular in the vertical (39 vs. 19 layers). The adjoint code of LMDz was initially developed for variational inversion, but we use this facility for the first time with LMDz in an analytical framework, to calculate the rows of the Jacobian Matrix $\mathbf{M}$ which correspond to the places where, and the times when, we have observations to assimilate. By definition, each value of $\mathbf{M}$ is a derivative of an output tracer concentration relative to an input surface flux or initial tracer value. More specifically, we use one adjoint run $\mathbf{M}^{T} \mathbf{y}^{*}$ for each observation to assimilate, with the elements of $\mathbf{y}^{*}$ set to zero or one. We use the Community Inversion Framework (CIF, Berchet et al. (2020)) to manage these computations.

In practice, we considered average synthetic observations at each selected measurement site (see Section 2.2.1) for each 8-day period between 2008 and 2019. For sites below $1000 \mathrm{~m}$ above sea level, only afternoon observations were used as the models do not simulate the accumulation of the tracers in the nocturnal boundary layer well (Locatelli et al., 2015). For elevated stations, both daytime and early nighttime observations were discarded because coarse-resolution models cannot represent the advection of air masses during the day by upslope winds over sunlit mountain slopes in the afternoon (Geels et al., 2007). After corresponding forward runs that defined the tracer linearization trajectories, the adjoint model was run nine months backward in time from measurement time for each of these synthetic observations (with appropriate $\mathbf{y}^{*}$ ), giving as output the series of integrated sensitivities of the corresponding measurement with respect to the surface fluxes throughout the nine months and to the concentrations at the initial point in time (forward-counted). For times prior to nine months, we have in fact not used the exact adjoint values. Instead, we extended the databases of adjoint outputs for the surface fluxes beyond the nine-month windows with two parts: (i) monthly adjoint outputs between months 9 and 24 taken from computations for the year 2017, and (ii) beyond 24 months, a globally-homogeneous value (i.e. $1 \mathrm{GtC}$ emitted at the surface is translated to an average concentration of $0.38 \mu \mathrm{mol} . \mathrm{mol}^{-1}$, or parts per million, ppm). We have verified that the $\mathrm{CO}_{2}$ and $\mathrm{COS}$ concentrations obtained by the resulting Jacobian matrix (Mx) match well the one given by the full LMDz transport model over the period (See Fig. S2 of the Supplementary).

In total, we have computed 15 stations $\times 12$ years $\times 2$ weeks $\times 12$ months adjoint computations of 8 process time hours each on a local parallel cluster. 
As explained below in Section 2.4.2, LMDz is complemented here for the modelling of COS in the atmosphere by a chemical sink, represented by a surface flux.

\subsection{Observations and data sampling}

\subsubsection{Assimilated observations: $\mathrm{COS}$ and $\mathrm{CO}_{2}$ surface sites}

5 We used the NOAA/ESRL measurements of both $\mathrm{CO}_{2}$ and COS between 2008 and 2019 at 15 sites whose location is depicted on Fig. 1: Cape Grim, Australia (CGO, $40.4^{\circ} \mathrm{S}, 144.6^{\circ} \mathrm{W}, 164 \mathrm{~m}$ above sea level, asl), American Samoa $\left(\mathrm{SMO}, 14.2^{\circ} \mathrm{S}, 170.6^{\circ} \mathrm{W}\right.$, $77 \mathrm{~m}$ asl), Mauna Loa, United States (MLO, 19.5 ${ }^{\circ} \mathrm{N}, 155.6^{\circ} \mathrm{W}, 3397 \mathrm{~m}$ asl), Cape Kumukahi, United States (KUM, $19.5^{\circ} \mathrm{N}$, $154.8^{\circ} \mathrm{W}, 3 \mathrm{~m}$ asl), Niwot Ridge, United States (NWR, $40.0^{\circ} \mathrm{N}, 105.54^{\circ} \mathrm{W}, 3475 \mathrm{~m}$ asl), Wisconsin, United States (LEF, $45.9^{\circ} \mathrm{N}$, $90.3^{\circ} \mathrm{W}, 868 \mathrm{~m}$ asl-inlet is $396 \mathrm{~m}$ above ground on a tall tower), Harvard Forest, United States $\left(\mathrm{HFM}, 42.5^{\circ} \mathrm{N}, 72.2^{\circ} \mathrm{W}, 340\right.$ $\mathrm{m}$ asl, inlet is $29 \mathrm{~m}$ aboveground), Barrow, United States (BRW, 71.3 $\mathrm{N}, 155.6^{\circ} \mathrm{W}, 8 \mathrm{~m}$ asl), Alert, Canada (ALT, 82.5 ${ }^{\circ} \mathrm{N}$, $62.3^{\circ} \mathrm{W}, 195 \mathrm{~m}$ asl), Trinidad Head, United States (THD, 41.0 $\mathrm{N}, 124.1^{\circ} \mathrm{W}, 120 \mathrm{~m}$ asl), Mace Head, Ireland (MHD, 53.3 ${ }^{\circ}$, $9.9^{\circ} \mathrm{W}, 18 \mathrm{~m}$ asl), Weizmann Institute of Science at the Arava Institute, Ketura, Israel (WIS, $29.96^{\circ} \mathrm{N}, 35.06^{\circ} \mathrm{E}, 151$ asl), Palmer Station, Antarctica, United States (PSA, 64.77 ${ }^{\circ} \mathrm{S}, 64.05^{\circ} \mathrm{W}, 10.0$ asl), South Pole, Antarctica, United States (SPO, $89.98^{\circ} \mathrm{S}$, $24.8^{\circ} \mathrm{W}, 2810.0 \mathrm{asl}$ ) and since mid-2004 at Summit, Greenland (SUM, 72.6 ${ }^{\circ} \mathrm{N}, 38.4^{\circ} \mathrm{W}, 3200 \mathrm{~m}$ asl). The COS samples have been collected as pair flasks one to five times a month since 2000 and have then been analysed with gas chromatography and mass spectrometry detection. Most measurements have been performed in the afternoon between 11 and $17 \mathrm{~h}$ local time when the boundary layer is well mixed. The COS measurements have been kept for this study only if the difference between the pair flasks is less than 6.3 ppt. These data represent an extension of the measurements first published in (Montzka et al., 2007).

The Jacobian Matrix M described in the previous section reveals the information content provided by these measurements in terms of tracer surface flux. In particular, it helps to identify to what extent each region of the globe is seen by the observations and therefore, it provides an indication of the details needed or not in the flux variables to be optimized. The transport sensitivities to the sources integrated over two months are represented in Fig. 1 on average for the period 2016-2019. The zonal distribution of sensitivities reflects the zonal atmospheric circulation at mid and high latitudes, with the north (south) stations seeing the entire domain above (under) $30^{\circ} \mathrm{N}$. Tropics are not well constrained by our observations: the inversion will not be able to partition the $\mathrm{COS}$ and $\mathrm{CO}_{2}$ components in this zone. The tropical circulation, mainly vertical, limits the extension of the footprint zone around SMO and MLO, leaving the Indo-Pacific region for the most part unconstrained. We also see that the southern and northern oceans are also more constrained by the observations than the continents, with the exception of North America which is relatively well covered by the measurements. Fig. 1 suggests the need to separate between each latitudinal band (Tropics, north and south latitudes) and also between oceans and continents in the inversion.

Note that, if computed with respect to the COS fluxes, the annual climatology of Jacobian shown on Fig. 1 would have the same spatial pattern but with a different unit given that the atmospheric transport is linear and there are no atmospheric chemical reactions. 


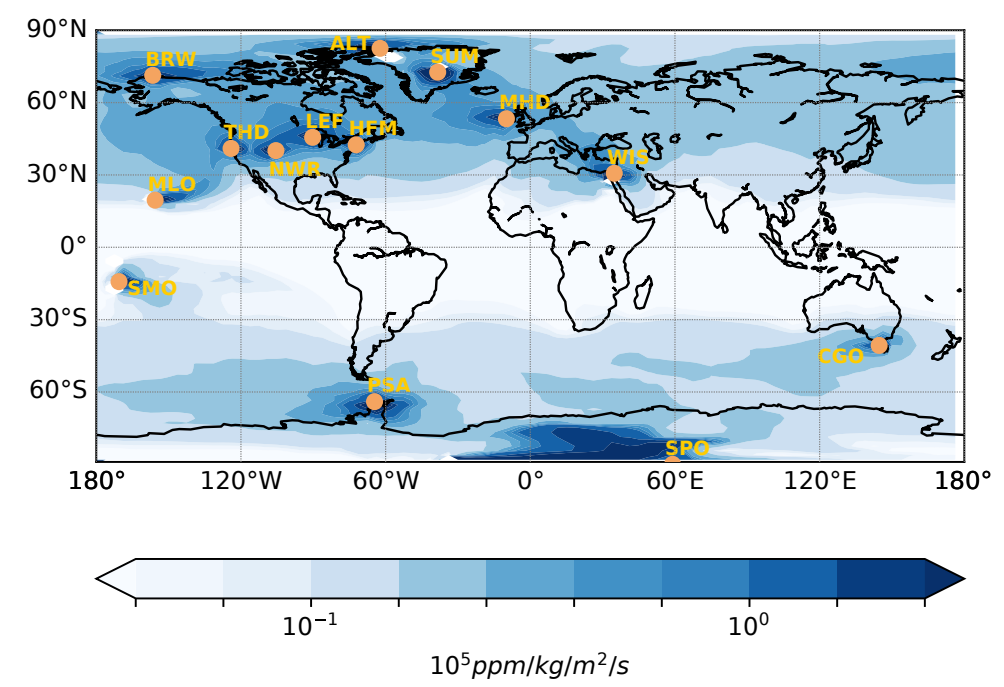

Figure 1. Annual climatology of Jacobians computed by the adjoint of the LMDz model: map of the partial derivatives, in $\mathrm{ppm} /\left(\mathrm{kg} / \mathrm{m}^{2} / \mathrm{s}\right)$, of a weekly mean concentration at all stations from the NOAA network with respect to $\mathrm{CO}_{2}$ surface fluxes in the previous month. The yellow dots denote the location of the surface sites. The site KUM is not depicted as it has the same coordinates than MLO.

\subsubsection{Independent observations}

An ensemble of independent observations - i.e. data that are not assimilated in LMDz - is used to evaluate the fluxes retrieved by our inverse system. We focus here on the observations used to evaluate the COS and the GPP fluxes.

The first observation program is the HIAPER Pole-to-Pole Observations (HIPPO, Wofsy (2011)). HIPPO consisted of five aircraft transects of many trace gas measurements, including for $\mathrm{COS}$ and $\mathrm{CO}_{2}$, in the troposphere over the Western Pacific: HIPPO 1 (January 2009), HIPPO 2 (November 2009), HIPPO 3 (March-April 2010), HIPPO 4 (June 2011) and HIPPO 5 (August 2011). The HIPPO measurements were made from flask and in-situ measurements by NOAA and the University of Miami. They were rescaled to be consistent with the calibration scale used for the NOAA surface network results.

In order to assess the North-South latitudinal COS gradient over Japan, surface measurements for winter and summer 2019 at three sampling site in Japan from Hattori et al. (2020) have been used as well: Miyakojima $\left(24^{\circ} 80 \mathrm{~N}, 125^{\circ} 27 \mathrm{E}\right)$, Yokohama $\left(35^{\circ} 51 \mathrm{~N}, 139^{\circ} 48 \mathrm{E}\right)$, and Otaru $\left(43^{\circ} 14 \mathrm{~N}, 141^{\circ} 16 \mathrm{E}\right)$. In winter, the Miyakojima site samples air masses strongly influenced by anthropogenic emissions from Chinese megacities including Beijing and Shanghai, while Yokohama and Otaru are only influenced by the northern periphery of China. During the summer, all sites mainly sample ocean air masses coming from southeastern Japan (Hattori et al., 2020).

The French sampling site, GIF ( $\left.48^{\circ} 42^{\prime} \mathrm{N}-2^{\circ} 08^{\prime} \mathrm{E}\right)$, is located about $20 \mathrm{~km}$ to the south west of Paris where ground level COS measurements have been monitored on a hourly basis since August 2014 (Belviso et al., 2020). According to the recent COS global gridded anthropogenic emission inventory of (Zumkehr et al., 2018), the Paris region is an important source of COS 
(791 MgS/yr, J. Stinecipher personal communication November 2018) where its indirect emissions from the rayon industry largely overpass its direct emissions from the aluminium industry and traffic. These estimates have been challenged by (Belviso et al., 2020). The location of the HIPPO data, NOAA airborne profiles, Japanese and GIF sites are depicted in Figure 2.

The fourth observation program is made of the satellite COS retrievals from MIPAS. The MIPAS spectrometer measured limb-emission spectra for several trace gases in the mid-infrared (Fischer et al., 2008) from the European Space Agency (ESA) Environmental Satellite (ENVISAT) between March 2002 and 2012. The IMK/IAA retrieval processor operated at KIT-IMK was used to calculate the COS profiles of data version $V 5 R_{O} C S_{2} 21 / 222$ which were used for this work (Glatthor et al., 2015, 2017). Between altitudes 7 and $25 \mathrm{~km}$ the accuracy of the COS profiles is around $50 \mathrm{ppt}$ in the absence of clouds (in particular deep-convective ones) (Glatthor et al., 2015).

Last, the SIF satellite retrievals from the Global Ozone Monitoring Experiment-2 (GOME-2) make it possible to evaluate the seasonality of GPP inferred by inverse modelling for each PFT. SIF represents the amount of light reemitted by chlorophyll molecules as a byproduct of photosynthesis. Satellite-based SIF data is considered as a proxy for the GPP of terrestrial ecosystems at large spatial-temporal scales (Frankenberg et al., 2011; Guanter et al., 2012; Zhang et al., 2016; Yang et al., 2015; Li et al., 2018). We use release number 28 of the NASA GOME-2 (Global Ozone Monitoring Experiment-2 onboard the MetOp-A satellite) daily corrected SIF product (Joiner et al., 2013, 2016). The dataset is available at: https : //avdc.gsfc.nasa.gov/pub/data/satellite/MetOp/GOME_F/v28/. We used the monthly level 3 product gridded at a $0.5^{\circ}$ resolution between years 2008 and 2019. This GOME-2 SIF product was shown to be very similar in terms of seasonality and magnitude (after spectral scaling) to the reference Orbiting Carbon Observatory (OCO-2, launched in 2014 , Sun et al. (2018)) data (Bacour et al., 2019). For each PFT, we average all the grid points within the LMDz grid points that have a fractional cover greater than 0.8. We lower this threshold to 0.3 for PFTs 7 (Boreal Broad-leaved Evergreen Forest), 8 (Boreal Broad-leaved Summergreen Forest), 9 (Boreal Needleleaf Summergreen Forest) and 15 (Boreal C3 grass). The PFTs are further defined in section 2.4 .

\subsubsection{Data sampling}

For each species and each measurement, the simulated concentration fields were sampled at the LMDz 3D grid box nearest to observation location. As mentioned above, the observations at selected local times are assimilated as 8-day averages. For the independent observations, LMDz is sampled at the closest time from the observations. All observations are dry-air mole fractions calibrated relative to (or, for the satellite retrievals, tuned to) the compound World Meteorological Organization (WMO) mole fraction scale. For comparison, the corresponding dry-air variables in the model simulations are used.

When comparing MIPAS data with LMDz simulations, the a priori and vertical sensitivity of the retrievals must be taken into account. For each MIPAS retrieval, the modelled COS profiles have been interpolated linearly to the MIPAS vertical resolution while ensuring the conservation of the column-average mixing ratio (Chevallier, 2015). They were then smoothed with the corresponding MIPAS averaging kernels.

The a priori profile for the COS retrievals is a zero profile (Glatthor et al., 2015), hence it had not to be taken into account. As done in Glatthor et al. (2015), we focus here on the spatial distribution of the COS mixing ratio at the $250 \mathrm{hPa}$ pressure 


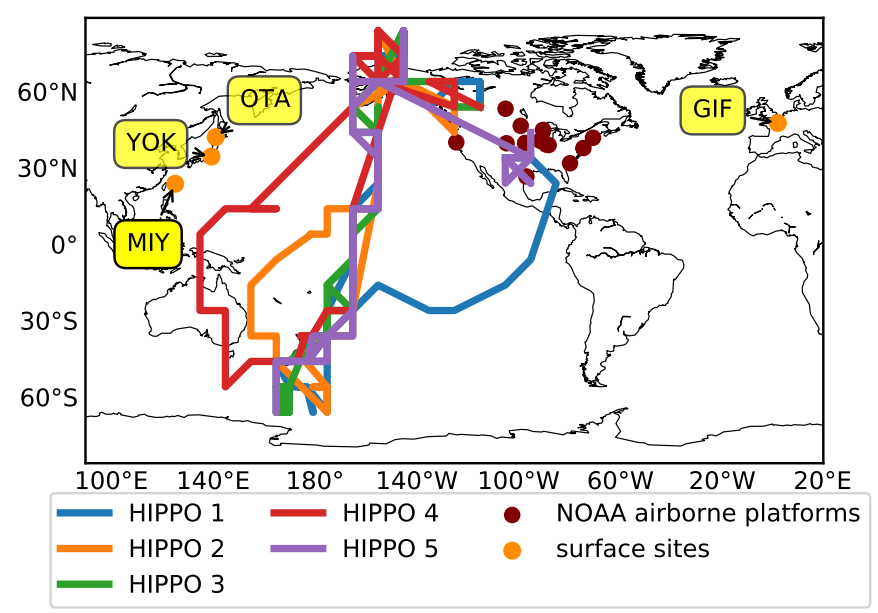

Figure 2. Location of the HIPPO airborne measurements, NOAA airborne platforms and surface sites in Japan and France that are used as independent observations for evaluating the inverse results. The HIPPO measurements have been averaged into bins of $10^{\circ}$ each. The NOAA airborne measurements are exploited in the Supplement.

level (still after convolution of the model with the averaging kernels) for the period 2008-2012. In order to dampen the random noise, we aggregate the retrievals into in $5^{\circ} \times 15^{\circ}$ latitude-longitude bins.

\subsection{Inverse framework}

Our inverse system seeks to estimate the amplitude of $n$ sources or sinks of $\mathrm{CO}_{2}$ and COS gathered in a vector $\mathrm{x}$ by reducing

the mismatch between the observed concentrations gathered in a vector $\mathbf{y}^{\mathbf{o}}$ and those simulated with the atmospheric transport model $\mathbf{M}$ forced by these sources and sinks. Together with an initial disaggregation operator (that converts the low-resolution control vector into gridded fluxes using gridded reference fluxes, see section 2.5.1) and a sampling operator (see previous section), the transport model $\mathbf{M}$ is part of the linear observation operator $\mathbf{H}$ that relates $\mathbf{x}$ and the model-equivalent $\mathrm{CO}_{2}$ and COS measurements $\mathbf{y}$ at the sites shown in Fig. 1:

$10 \mathbf{y}=\mathbf{H x}$

In order to regularize the inverse problem corresponding to Eq. (1), we use a Bayesian framework involving an a priori control vector, $\mathbf{x}^{\mathbf{b}}$ with its associated uncertainty statistics, summarized in covariance matrix $\mathbf{B}$. Within the Gaussian assumption of the prior and observations errors, the solution of the inverse problem can be simply expressed by the following equation (see for instance Tarantola (1989)) for the the posterior control vector $\mathbf{x}^{\mathbf{a}}$ and the uncertainty covariance matrix $\mathbf{P}^{a}$ :

$$
\mathbf{x}=\mathbf{x}^{\mathbf{b}}+\mathbf{B} \mathbf{H}^{\mathbf{T}}\left(\mathbf{H B H} \mathbf{H}^{\mathbf{T}}+\mathbf{R}\right)^{-\mathbf{1}}\left(\mathbf{y}^{\mathbf{o}}-\mathbf{H} \mathbf{x}^{\mathbf{b}}\right)
$$

$\mathbf{P}^{a}=\mathbf{B}-\mathbf{B H}^{T}\left(\mathbf{H B H} \mathbf{H}^{T}+\mathbf{R}\right)^{-1} \mathbf{H B}$ 
with $\mathbf{R}$ the error covariance matrix of the observations, encompassing measurement errors and $\mathbf{H}$ errors. Within the Gaussian assumption with no bias for all errors, the above solution minimizes the cost function :

$J(\mathbf{x})=\frac{\mathbf{1}}{\mathbf{2}}\left[(\mathbf{y}-\mathbf{H x})^{\mathbf{T}} \mathbf{R}^{-\mathbf{1}}\left(\mathbf{y}^{\mathbf{o}}-\mathbf{H x}\right)+\left(\mathbf{x}-\mathbf{x}^{\mathbf{b}}\right)^{\mathbf{T}} \mathbf{B}^{-\mathbf{1}}\left(\mathbf{x}-\mathbf{x}^{\mathbf{b}}\right)\right]$

\subsection{Gridded reference fluxes}

5 In the following, we call "reference fluxes" the maps of $\mathrm{CO}_{2}$ and $\mathrm{COS}$ fluxes that are used in the observation operator, the control vector $\mathrm{x}$ being a low-resolution multiplier to these (see Section 2.5 .1 ). For use at resolution $3.75^{\circ} \times 1.90^{\circ}$, the maps of the following components of the $\mathrm{CO}_{2}$ and $\mathrm{COS}$ fluxes have been interpolated from their native resolution. All projections conserved mass.

\subsection{1 $\mathrm{CO}_{2}$ fluxes}

Our reference fluxes combine several information sources. Fossil fuel emissions are from the gridded fossil emission dataset GCP-GridFED (version 2019.1) (Jones et al., 2021). Biomass burning fluxes vary inter-annually and are described by the GFED 4.1s database (https://www.globalfiredata.org/data.html). Monthly air-sea $\mathrm{CO}_{2}$ exchange is prescribed from the Copernicus Marine Environment Service database (Denvil-Sommer et al., 2019). The GPP and respiration fluxes have been simulated at a resolution of $0.5^{\circ}$ both in longitude and latitude by the ORCHIDEE land surface model (Krinner et al., 2005). ORCHIDEE explicitly parameterizes the main processes influencing the water, carbon and energy balances at the interface between land surfaces and atmosphere. The vegetation is represented by 15 PFTs with a spatial distribution prescribed from the ESA Climate Change Initiative (CCI) land cover products (Poulter et al., 2015). The plant phenology is prognostic and PFT-specific. We used version 9 tuned for the CMIP6 exercise and forced by the global CRUJRA reanalysis at global scale (https://sites.uea.ac.uk/cru/data/) v1-v2, applying land-use change and realistic increase of $\mathrm{CO}_{2}$ atmospheric concentration. Emissions from the land use and wood harvest have been included beforehand in the respiration term. Biomass burning emissions are not taken into account in this respiration term from ORCHIDEE. The yearly global GPP from ORCHIDEE amounts to 126.7 GtC. $\mathrm{y}^{-1}$ during 2008-2019. This value is within the range of the GPP estimates (106-137 GtC.yr ${ }^{-1}$ ) based on photosynthesis proxies (see Table S1) (Beer et al., 2009, 2010; Welp et al., 2011; Alemohammad et al., 2017; Jasechko, 2019; Jung et al., 2020; Ryu et al., 2011; Badgley et al., 2019; Stocker et al., 2019). The PFTs and their acronyms are defined in Table 1. Note that GPP, respiration, COS vegetation and soil fluxes are null within PFT 1.

\subsubsection{COS fluxes}

The components of the COS budgets that are considered are biomass burning, soil emissions and sink, anthropogenic emissions, plant uptake, oceanic emissions and the atmospheric oxidation by the $\mathrm{OH}$ radical in the troposphere. Photolysis in the stratosphere, estimated to $30 \mathrm{GgS} . \mathrm{yr}^{-1}$ in the LMDz atmospheric transport model (not shown), and volcano emissions, in the range 23-43 ${\mathrm{GgS} . \mathrm{yr}^{-1}}^{-1}$, have been neglected (Whelan et al., 2018).

\section{Soil}




\begin{tabular}{lc} 
PFT & Acronym \\
\hline 1 - Bare soil & BaS \\
2 - Tropical Broad-leaved Evergreen Forest & TrBrE \\
3 - Tropical Broad-leaved Raingreen Forest & TrBrR \\
4 - Temperate Needleleaf Evergreen Forest & TeNeE \\
5 - Temperate Broad-leaved Evergreen Forest & TeBrE \\
6 - Temperate Broad-leaved Summergreen Forest & TrBrS \\
7 - Boreal Needleleaf Evergreen Forest & BoNeE \\
8 - Boreal Broad-leaved Summergreen Forest & BoBrS \\
9 - Boreal Needleleaf Summergreen Forest & BoNeS \\
10 - Temperate C3 Grass & TeC3g \\
11 - C4 Grass & C4g \\
12 - C3 Agriculture & C3Ag \\
13 - C4 Agriculture & C4Ag \\
$14-$ Tropical C3 grass & TrC3g \\
$15-$ Boreal C3 grass & BoC3g
\end{tabular}

Table 1. List of the PFTs as defined in the ORCHIDEE LSM.

\begin{tabular}{|c|c|c|c|c|c|c|c|c|}
\hline & PROCESSES & Kettle et al. (2002) & Montzka et al. (2007) & Suntharalingam et al. (2008) & Berry et al. (2013a) & Launois et al. (2015b) & Ma et al. (2021) & This study \\
\hline \multirow[t]{4}{*}{ SOURCES } & Anthropogenic & 180 & 180 & 180 & 180 & 180 & 349 & 398 \\
\hline & Oceanic & 296 & 296 & 230 & $876 \dagger$ & 1027 & 277 & 269 \\
\hline & Biomass Burning & 38 & 106 & 70 & 136 & 70 & 136 & 53 \\
\hline & Anoxic Soils & 26 & 26 & 26 & neglected & 101 & neglected & neglected \\
\hline \multirow[t]{3}{*}{ SINKS } & Oxic soils & -130 & -130 & -130 & -355 & -510 & & -236 \\
\hline & Plant uptake & -238 & -1115 & -490 & -738 & -1335 & -1053 & -657 \\
\hline & Atmospheric chemical loss & -121 & -121 & -121 & -101 & -100 & -141 & -100 \\
\hline TOTAL & & 52 & -757 & -234 & -1 & -567 & $-432 \ddagger$ & -273 \\
\hline
\end{tabular}

Table 2. Overview of the global budget of COS. Units are GgS. $\mathrm{yr}^{-1}$.

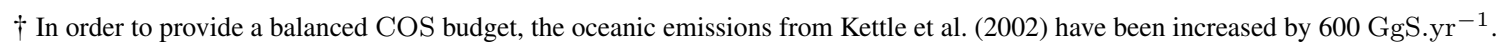

$\ddagger$ This unknown source has been optimized using a 4- dimensional variational data-assimilation system. over the globe.

Reference air-surface exchanges from oxic soils have been simulated by the steady-state analytical model of Ogée et al. (2016) implemented in the ORCHIDEE land surface model with the Zobler soil classification at a $0.5^{\circ}$ both in longitudes and latitudes. This model is built on the assumptions that the soil atmosphere exchanges are governed by three processes, namely diffusion through the soil column, production and irreversible uptake via hydrolysis. The COS uptake means to reflect for the to what happens in plants. The CA activity is represented by the CA enhancement factor or $f_{C A}$, which is PFT-specific and has been calibrated against measurements performed by Meredith et al. (2018) on different biomes in the laboratory. The production term simulates the COS abiotic production from soils via the Whelan et al. (2016) model. Its exponential increase 
with temperature decreases the net soil uptake over the tropics and in mid-latitudes in summer. The soil model has been shown to be in better agreement with measurements than the Berry et al. (2013a) model used in previous top-down studies. ). A complete validation of the soil fluxes in ORCHIDEE will be the topic of a future publication. As for the contribution of anoxic soils (Whelan et al., 2013), we have not taken them into account in the absence of reliable emission maps (Whelan et al., 2018).

We chose the empirical formulation of the COS uptake by leaves from Sandoval-Soto et al. (2005) given by the linear relationship

$F_{C O S}=G P P \times \frac{[C O S]}{\left[\mathrm{CO}_{2}\right]} \times \frac{v_{C O S}}{v_{C O_{2}}}$

In this equation, $F_{C O S}$ and $G P P$ are the $\mathrm{COS}$ uptake and the $\mathrm{CO}_{2}$ uptake (both in $\mathrm{pm} / \mathrm{m}^{2} / \mathrm{s}$ ), respectively, $[C O S]$ and $\left[\mathrm{CO}_{2}\right]$ being the ambient air concentrations of $\mathrm{COS}$ and $\mathrm{CO}_{2} \cdot v_{C O S}$ and $v_{\mathrm{CO}_{2}}$ are the $\mathrm{COS}$ and $\mathrm{CO}_{2}$ leaf uptake velocities. The ratio of uptake velocities of COS compared to $\mathrm{CO}_{2}$ is defined as the LRU:

$L R U=\frac{v_{C O S}}{v_{C O_{2}}}$

We use a zero-order LRU approach (i.e. with no interaction between vegetation and COS mixing ratio), given the complexity of a one-order approach (i.e. a coupled atmospheric COS concentration - COS flux calculation). To address this shortcoming, we use the time-evolving hemispheric means of the $\mathrm{COS}$ and $\mathrm{CO}_{2}$ atmospheric concentrations, $N H_{\text {mean }}$ and $N S_{\text {mean }}$ as done in Montzka et al. (2007). They are computed from monthly means at selected stations in this way:

$S H_{\text {mean }}=[S P O \times 0.408+C G O \times 0.770+S M O \times 0.974] /[0.408+0.770+0.974]$

$$
\begin{array}{r}
N H_{\text {mean }}=[(K U M+M L O) \times 0.970 / 2+(L E F+N W R+H F M) \times 0.751 / 3 \\
+(B R W+A L T) \times 0.402 / 2] /[0.970+0.751+0.402]
\end{array}
$$

We have only made a distinction between C4 (LRU=1.21) and C3 plants (LRU=1.68) and disregarded the dependence on light and water vapor deficit that was observed at both leaf (Stimler et al., 2010) and ecosystem scales (Commane et al., 2015; Kooijmans et al., 2019). Our LRU set is derived from Whelan et al. (2018) and uses, for C3 plants, the median value of 53 LRU data and, for C4 plants, the median value of 4 LRU data. This simplification is supported by Hilton et al. (2017); Campbell et al. (2017) who showed that the uncertainty on the LRU parameter is of a second order importance compared to the uncertainties on the GPP and the other COS fluxes. Morevoer, Maignan et al. (2020) showed that using a mechanistic model or its LRU equivalent model (i.e. with a constant LRU per PFT in ORCHIDEE LSM) for the plant uptake leads to similar results when transporting the COS fluxes with LMDz and comparing the COS concentrations at stations of the NOAA network. We have not taken into account the epyphites which can both emit and absorb COS depending on environmental conditions (Kuhn and Kesselmeier, 2000; Rastogi et al., 2018). 
For anthropogenic fluxes, we use the inventory of Zumkehr et al. (2018) for the period 1980-2012 that corresponds to a global

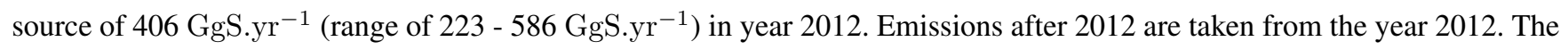
inventory accounts for direct COS emissions and indirect emissions through the oxidation of $\mathrm{CS}_{2}$ into the atmosphere. Are considered, in order of importance: emissions from rayon (staple and yarn) industry, residential coal, pigments, aluminium melting, agricultural chemicals and tires. Compared to Kettle et al. (2002), the majority of the sources has shifted over time from the US to China which encompasses now $45 \%$ of the total emissions.

\section{Ocean}

COS is directly emitted by the ocean in places where the sea water is saturated in COS. Emissions typically happen in summer in high latitudes. COS is also indirectly emitted through the oxidation of DMS and $\mathrm{CS}_{2}$ in the atmosphere, which are both produced in seawater. We use the indirect and direct COS emissions from Lennartz et al. $(2017,2020 \mathrm{a})$ whose total emissions account for $285 \mathrm{GgS} . \mathrm{yr}^{1}$. In these, direct, indirect emissions via $\mathrm{CS}_{2}$ and DMS from the global ocean account for $130 \pm 80$ GgS.yr ${ }^{-1}, 74 \pm 120$ GgS.yr ${ }^{-1}$ and $65-110$ GgS.yr $^{-1}$, respectively. These emissions have been all computed using box models calibrated with ship-borne measurements made in different parts of the globe (Lennartz et al., 2017, 2020a). The DMS emissions are taken from the Lana et al. (2011) climatology. The latitudinal distributions of each of the three terms of the oceanic emissions are depicted on Fig. 3.

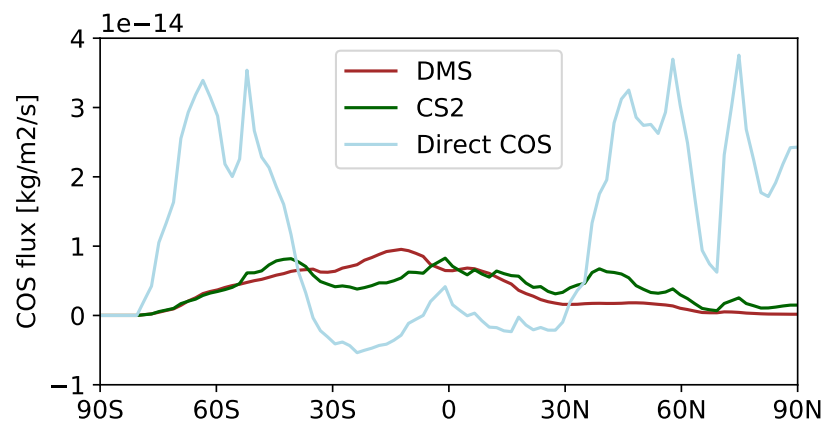

Figure 3. Zonal mean distribution of the prior oceanic fluxes as a function of latitude averaged over the year 2010. The direct COS emissions are shown in blue whereas the indirect COS emissions through DMS $\left(\mathrm{CS}_{2}\right)$ are depicted in brown (green). Direct COS emissions are shown in green.

We have not considered DMS and $\mathrm{CS}_{2}$ as separate tracers as done in Ma et al. (2021). $\mathrm{CS}_{2}$ has a lifetime estimated between 4 days (Khan et al., 2017) and 12 days (Khalil and Rasmussen, 1984) and DMS has a lifetime of 1.2 days. For the sake of simplicity, the oxidation of $\mathrm{CS}_{2}$ and DMS by $\mathrm{OH}$ has been assumed to happen instantly in the atmosphere.

\section{Biomass burning}

We use the inventory emissions from Stinecipher et al. (2019) with a global estimate of $60 \pm 37 \mathrm{GgS}_{\mathrm{yr}}{ }^{-1}$ for the period 1997-2016. These authors used CO as a reference species to compute the COS biomass burning emissions. To do that, they combined emission factors of $\mathrm{COS}$ to $\mathrm{CO}$ from the literature and applied them to the $\mathrm{CO}$ emissions. These $\mathrm{CO}$ emissions were computed beforehand from the GFED Global Fire Emissions Database (GFED version 4, https://www.globalfiredata.org/). 
The resulting biomass emissions are classified into four categories: savanna and grassland, boreal forests, temperate forests, tropical deforestation and degradation, peatland fires, and agricultural waste burning. The savanna was shown to be the largest contributor to the global biomass burning emissions and therefore to the overall uncertainty. These new estimates are lower than the previous estimation as these were positively biased by a strong emission factor derived from measurements over the peatlands. Moreover, their weak inter-annual variability was shown to better reproduce the annual trend in atmospheric concentration at the Jungfraujoch station, the long-term trend being primarily driven by changes in anthropogenic activity (Zumkehr et al., 2017).

\section{OH sink}

Since the highest reaction rate is close to the surface (Kettle et al., 2002), we represent the OH sink by a surface flux. As done in Launois et al. (2015b), we take the spatial patterns of monthly maps of the $\mathrm{OH}$ radical concentrations and we distribute

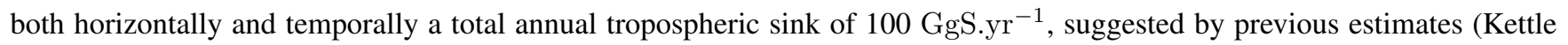
et al., 2002; Berry et al., 2013b). We use monthly maps of OH radical concentrations from an update of Hauglustaine et al. (2004).

\subsection{Inversion configuration}

\subsubsection{Control vector}

Our inversion window covers 12 years. The spatiotemporal resolution of the control vector $\mathbf{x}$ over this period represents a compromise between the assumed resolution of the errors of the reference fluxes, the expected resolution of the flux increments that can be inferred by the sparse site distribution (see Figure 1), and considerations on computing time. Typically, a large control vector (i.e. many controlled regions and types of emission) may represent the complexity of reality better than a small one (i.e. few regions and emission processes), but also increases the inversion calculation load without always improving inversion skill, given the scarce and uneven observation network. The variables in the control vector are therefore all multipliers of the above-described gridded reference fluxes, as described as follows, rather than grid-point fluxes themselves. The choice of multipliers rather than increments implies that the initial sub-control-scale patterns are kept. The prior control vector $\mathbf{x}^{\mathbf{b}}$ is simply a vector of ones.

We control COS oceanic fluxes in three latitudinal bands : the tropics, the northern latitudes and the southern latitudes. This separation allows the inverse system to modify the latitudinal distribution of the reference emissions, which remains subject to large uncertainties, while preserving the prior longitudinal patterns. This amounts to saying that the coastal sites located in the northern hemisphere constrain the total oceanic emissions over the whole northern hemisphere above $30^{\circ} \mathrm{N}$. On the continents, for respiration, GPP and soil fluxes, we distinguish the two hemispheres for eight of the 15 PFTs which are present in both (4, $5,6,10,11,12,13$, see Table 1) to take into account the different seasonality. For the anthropogenic COS emissions, we control a single annual emission coefficient and rely on the reference distribution of sources between Europe, Asia and America: the lack of observations in the Asia-Pacific region does not allow us to separately optimize Asian emissions. All parameters are 
optimized on a monthly scale with the exception of anthropogenic emissions which are assumed to be constant throughout the year.

For the $\mathrm{CO}_{2}$, we neglect the uncertainty on the oceanic, fire and anthropogenic $\mathrm{CO}_{2}$ emissions compared to that of the sum of the respiration and GPP. The parameters of the control vector are described in Table 3.

\begin{tabular}{l|cccccc}
\hline Parameters & species & number of PFTs & number of regions & frequency & units & number of parameters \\
\hline Oceanic fluxes & $\mathrm{COS}$ & 0 & $3 \dagger$ & monthly & $\mathrm{GgS}$ & 36 \\
Soil fluxes & $\mathrm{COS}$ & 15 & $2 \ddagger$ & monthly & $\mathrm{GgS}$ & 4140 \\
GPP & $\mathrm{CO}_{2}-\mathrm{COS}$ & 15 & $2 \ddagger$ & monthly & $\mathrm{GtC}$ & 4140 \\
Respiration & $\mathrm{CO}_{2}$ & 15 & $2 \ddagger$ & monthly & $\mathrm{GtC}$ & 4140 \\
Anthropogenic emissions & $\mathrm{COS}$ & 0 & 1 & annual & $\mathrm{GgS}$ & 1 \\
Biomass burning emissions & $\mathrm{COS}$ & 0 & 1 & monthly & $\mathrm{GgS}$ & 12 \\
Background concentration & $\mathrm{CO} 2$ & 1 & 1 & monthly & $\mathrm{ppm}$ & 1 \\
Background concentration & $\mathrm{COS}$ & 1 & 1 & monthly & $\mathrm{ppt}$ & 1 \\
\hline
\end{tabular}

Table 3. Controlled variables for one year. The size of the control vector is equal to 149630 for the inversion period $2008-2019$.

$\dagger$ The ocean flux is divided into 3 regions : $30^{\circ} \mathrm{N}: 90^{\circ} \mathrm{N}, 90^{\circ} \mathrm{S}: 30^{\circ} \mathrm{S}, 30^{\circ} \mathrm{S}: 30^{\circ} \mathrm{N}$.

$\ddagger$ GPP, respiration and soil fluxes of PFTs $4,5,6,10,11,12,13$ are divided into 2 hemispheres : $\mathrm{O}^{\circ} \mathrm{N}: 90^{\circ} \mathrm{N}, 0^{\circ} \mathrm{S}: 90^{\circ} \mathrm{S}$.

\section{2.5.2 Prior and observation error covariance matrices}

Observation errors are defined with respect to the observation operator $\mathbf{H}$ and are actually dominated by the errors of $\mathbf{H}$. As explained in Section 2.3, $\mathbf{H}$ is made of a disaggregation operator, a transport model and a sampling operator. For the transport model error statistics, we follow the detail of the approach described by Chevallier et al. (2010) who used the statistics of the difference between the raw times series and the corresponding smooth curve as a proxy. This approach yields one error standard deviation per station. The procedure to derive the smooth curve is explained in Section 2.6. We doubled the resulting standard deviation at each station in order to account for the error induced by the disaggregation operator. The error is likely larger at stations NWR, LEF, HFM and WIS partly because of the larger influence of nearby fluxes and we have applied an additional twofold factor there. For instance, LEF is located in the Midwestern States, a region contributing half of the summer carbon uptake in North America (Sweeney et al., 2015). Similarly, the standard deviation is also multiplied by two at station SMO further to the challenging representation of sub-grid-scale transport by deep convective clouds in the Tropics. The resulting observation error standard deviation at each stations is shown in Figure 5.

Our prior error covariance matrix $\mathbf{B}$ (that applies to $\mathbf{x}^{\mathbf{b}}$, a vector of ones, cf. Section 2.5.1) is described in Table 4. Although the large number of parameters offers very diverse possibilities for the definition of the error covariance matrix, we present only one scenario that is optimal in terms of fit to observations among those that we find compatible with our knowledge of the errors of the reference maps. For instance: 
a) $\mathrm{CO} 2$

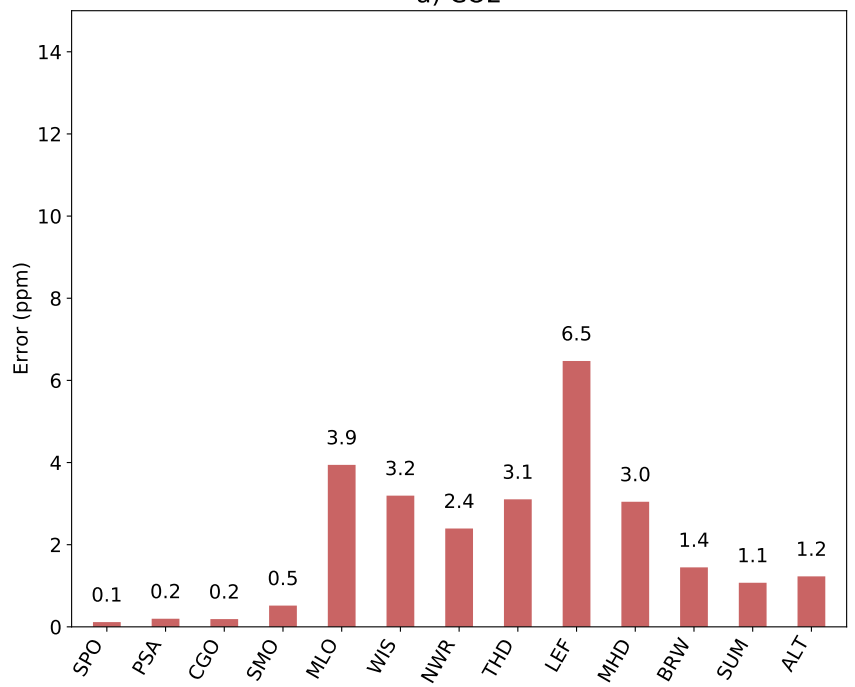

b) $\cos$

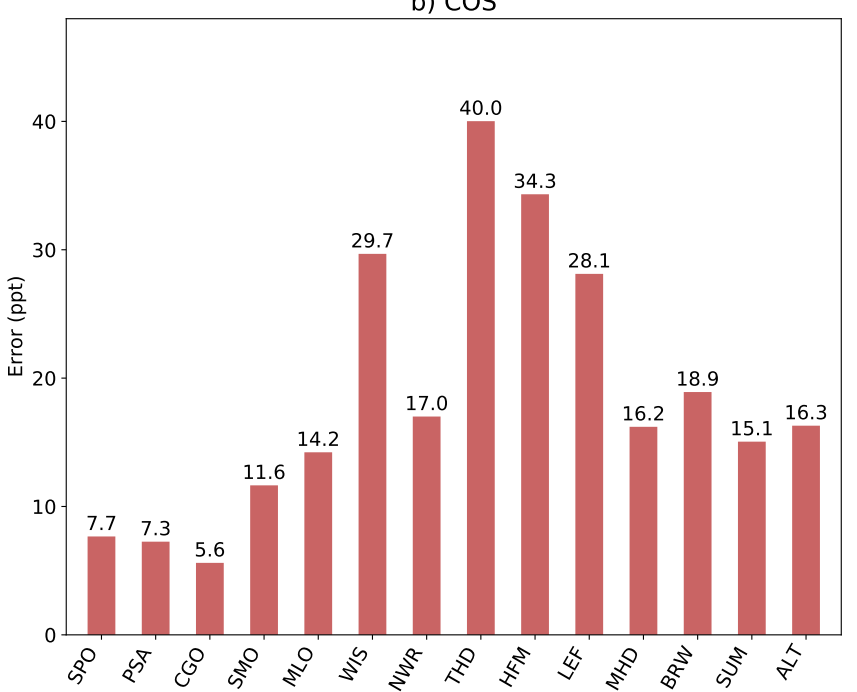

Figure 4. Assigned error standard deviations for each station and for a) $\mathrm{CO}_{2}$ and b) COS. Stations are ordered from the South Pole (on the left) to the North Pole (on the right).

\begin{tabular}{|c|c|c|c|c|c|}
\hline & Oceanic fluxes & Soil fluxes & $\begin{array}{c}\text { GPP and } \\
\text { Respiration }\end{array}$ & $\begin{array}{l}\text { Biomass burning } \\
\text { emissions (COS) }\end{array}$ & $\begin{array}{c}\text { Anthropogenic } \\
\text { emissions }\end{array}$ \\
\hline Error standard deviation & 2.0 & 0.3 & $0.1-0.2$ & 0.9 & 0.5 \\
\hline $\begin{array}{l}\text { Lag-1 autocorrelation coefficient } \\
\text { (temporal correlation in days) }\end{array}$ & $0.5(60)$ & $0.9(100)$ & $0.9(90)$ & $0.5(60)$ & $0.5(500)$ \\
\hline Correlations between PFTs & - & $0.5-0.6$ & $0.5-0.6$ & - & - \\
\hline
\end{tabular}

Table 4. Description of the prior error covariance matrix. Since the control vector is made of low-resolution multipliers to reference maps, the standard deviations are fractions of the reference values. The lag-1 autocorrelation coefficients are the correlations assigned between two consecutive time steps for each controlled variable, the time step being defined in Table 3.

- GPP and respiration. The monthly-mean GPP fom ORCHIDEE within each of the PFTs agrees with site-level GPP estimates from eddy covariance measurements in the range of $20 \%$ (not shown). For PFT 2 (Tropical Broad-leaved Evergreen Forests), we reduce the 1-sigma uncertainty to $10 \%$, a more realistic value given the large gross fluxes over the tropics. We introduce some non diagonal terms in the prior error covariance matrix to represent likely error correlations between PFTs given that they share for most processes the same equations in the ORCHIDEE model. Thus, the errors in the PFTs mainly located over the high latitudes (PFTs 7, 8, 9, 15), the mid-latitudes (PFTs 4, 5, 6, 10), the tropics (PFTs 2, $3,11,14$, see Table 1 for a description of the PFTs) are set to be correlated with a factor $0.6,0.5$ and 0.6 , respectively. We 
further introduce temporal correlations for GPP and respiration. At the first order, we expect that the errors associated to the monthly GPP simulated by ORCHIDEE are positively correlated because: i) errors in the structure of the ORCHIDEE model likely lead to positively correlated flux errors, ii) parametric errors will also provide similar correlations. However, errors in the meteorological forcing may de-correlate the gross flux errors, which could justify for an exponential decay as a function of time. Memory effect linked for example to soil moisture (and thus precipitation) may also induce error correlation (Stocker et al., 2019). For the annual global GPP, this set-up leads to a 1-sigma uncertainty of 5 GtC.yr ${ }^{-1}$ for a reference value here of $125 \mathrm{GtC} \cdot \mathrm{yr}^{-1}$ : this uncertainty may look small compared with the range of GPP estimates found in the literature (see Table S1) but is in agreement with the most recent estimation of $125 \pm 5.2 G t C . y r^{-1}$ from Stocker et al. (2019). The same set-up has been chosen for plant respiration. There are error correlations between GPP and respiration but these are neglected in this study.

- Oceanic emissions. Our resulting 1-sigma uncertainty of $350 \mathrm{GtC} \cdot \mathrm{yr}^{-1}$ for the globe and the year, given a reference value of 271 GtC.yr ${ }^{-1}$ (see Fig. 4), is consistent with Lennartz et al. (2017, 2019, 2020a) who estimated the ocean emissions between 120 - 600 GgS.yr ${ }^{-1}$.

- Anthropogenic emissions. Our correlation length of 500 days damps interannual variations, consistent with Zumkehr et al. (2018) who found that they do not vary by more than $5 \%$ from one year to the next. The resulting 1-sigma uncertainty of 197 GtC.yr ${ }^{-1}$ for the globe and the year, given a reference value of 370 GtC.yr ${ }^{-1}$ (see Fig. 4), is consistent with the estimation of 223-586 GgS.yr ${ }^{-1}$ given by Zumkehr et al. (2018).

- Soil fluxes. Our choice of a standard deviation of $30 \%$ is rather arbitrary given the lack of measurements to evaluate the reference soil flux within each PFT. We also assign a large autocorrelation length (100 days) to damp month-to-month variations, consistent with local measurements made at Harvard and Gif-Sur-Yvette (Belviso et al., 2020; Commane et al., 2015).

\subsection{Post-processing of the $\mathrm{CO}_{2}$ and $\mathrm{COS}$ simulations and measurements}

The seasonal cycle is derived from the surface data using the CCGVU curve fitting procedure developed by Thoning et al. (1989) (http://www.esrl.noaa.gov/gmd/ccgg/mbl/crvfit/crvfit.html). The procedure estimates a smooth function by fitting the time series to a first order polynomial equation for the growth rate combined with a two-harmonic function for the annual cycle, nd a low-pass filter with 80 and 667 days as short-term and long-term cutoff values, respectively.

\subsection{Consistency metrics}

The global $\chi^{2}$ is equal to twice the cost function $J(\mathbf{x})$ at its minimum (see Equation 3 for the general definition of the cost function):

$30 \chi^{2}=(\mathbf{y}-\mathbf{H x})^{\mathbf{T}} \mathbf{R}^{-\mathbf{1}}\left(\mathbf{y}^{\mathbf{o}}-\mathbf{H x}\right)+\left(\mathbf{x}-\mathbf{x}^{\mathbf{b}}\right)^{\mathbf{T}} \mathbf{B}^{-\mathbf{1}}\left(\mathbf{x}-\mathbf{x}^{\mathbf{b}}\right)$ 
This metric allows us to check the consistency of the error covariance matrices. The $\chi^{2}$ follows the so-called chi-square law, with the the number of degrees of freedom equal to the number of observations $\left(N_{o b s}\right)$ (as in our case the observation error covariance matrix is diagonal). The ratio $\chi^{2} / N_{o b s}$ (normalized $\chi^{2}$ ), should therefore be close to 1 . This means that the residuals between observed and simulated concentrations should be aligned with the assigned measurement errors, and the residuals should be distributed as a Gaussian around the observed values. A value larger (respectively smaller) than 1 may indicate that the assigned uncertainties (of the measurements and/or from the a priori fluxes) are too small (respectively too large). However, tuning the prior and observation covariance matrices with the sole normalized $\chi^{2}$ may actually be misleading since the matrices involve many variables (including outside the diagonal) that may play compensating roles in the $\chi^{2}$ (Chevallier, 2007).

The $\chi^{2}$ per station, $\chi_{i}^{2}$, represents the contribution of each site to the first term of the global $\chi^{2}$. For a station $i$, the metric is defined as:

$\chi_{i}^{2}=\left(\mathbf{y}_{\mathbf{i}}-\mathbf{H x}_{\mathbf{i}}\right)^{\mathbf{T}} \mathbf{R}_{\mathbf{i}}^{-\mathbf{1}}\left(\mathbf{y}_{\mathbf{i}}^{\mathbf{o}}-\mathbf{H} \mathbf{x}_{\mathbf{i}}\right)$

with $\mathbf{y}_{\mathbf{i}}$ and $\mathbf{y}_{\mathbf{i}}^{\mathbf{o}}$ being the simulated and observed concentrations at station i. This value, divided by $N_{o b s}$ (normalized $\chi_{i}^{2}$ ), should ideally be close to 1 . A value larger (respectively smaller) than 1 may indicate that the assigned uncertainties of the measurements at this station are too small (respectively too large).

\section{Inverse results}

\subsection{Comparison to the assimilated surface measurements}

Table 5 shows the error reduction achieved by the inversion in terms of RMSE between the simulated and the observed concentrations. As expected, the inverse system has reduced the observation-model mismatch by about $85 \%$ at most stations. Of interest in Table 5 is also the error reduction for the detrended smooth curves in which only seasonal variations are retained. It is indeed important to accurately represent the large $\mathrm{COS}$ and $\mathrm{CO}_{2}$ surface depletion in spring as it mainly reflects the amplitude of the GPP over the continents. The seasonal error reduction is usually smaller than the raw error reduction: the COS inversion mainly corrects the negative tendency in $\mathrm{COS}$ mixing ratio arisen from the unbalanced prior budget. For instance at MLO between 2008 and 2011, the tendency of the $\mathrm{CO}_{2}$ (COS) concentrations a priori is 3.9 ppm.yr ${ }^{-1}\left(-57 \mathrm{ppt}_{\mathrm{yr}}{ }^{-1}\right)$ against $2.0 \mathrm{ppm} . \mathrm{yr}^{-1}\left(1.4 \mathrm{ppt} . \mathrm{yr}^{-1}\right)$ in the observations. Yet, the inversion has reduced the seasonal misfits to observations at most sites except at LEF and MLO for $\mathrm{CO}_{2}$ and MLO, THD, WIS for COS. At the northernmost sites (ALT, BRW, SUM, MHD), the error reduction exceeds $50 \%$ for both compounds. Despite some improvements, the inversion still struggles to represent the seasonal cycle of the COS measurements at sites WIS, HFM, THD for which the RMSE remains greater than 15 ppt. THD is a coastal station which suffers from the influence of fluxes nearby (Riley et al., 2005). For this reason, modelling the variability of its $\mathrm{CO}_{2}$ and $\mathrm{COS}$ mixing ratio has been shown to be particularly challenging (Ma et al., 2021). The inverse system also struggles to match $\mathrm{CO}_{2}$ measurements at sites WIS, NWR, HFM, LEF with a seasonal RMSE greater than $1.5 \mathrm{ppm}$.

The consistency of the estimate with the measurement errors and the a priori flux errors assumed is analyzed first with the global normalized chi-squared statistic (see Section 9). This metric should ideally be close to 1 . In our case, the normalized $\chi^{2}$ 


\begin{tabular}{|c|c|c|c|c|c|}
\hline \multicolumn{7}{|c}{ COS } \\
\hline station & $R E$ & $R M S E_{\text {prior }}^{\text {seas }}$ & $R M S E_{\text {post }}^{\text {seas }}$ & $R E^{\text {seas }}$ & $\chi^{2}$ \\
\hline ALT & 0.8 & 39.14 & 8.07 & 0.79 & 1.2 \\
\hline BRW & 0.83 & 44.68 & 6.85 & 0.85 & 0.7 \\
\hline CGO & 0.95 & 19.4 & 3.93 & 0.8 & 1.2 \\
\hline LEF & 0.8 & 20.58 & 10.24 & 0.5 & 0.7 \\
\hline MHD & 0.84 & 33.29 & 10.44 & 0.69 & 1.0 \\
\hline MLO & 0.9 & 6.24 & 7.48 & -0.2 & 0.9 \\
\hline NWR & 0.89 & 8.84 & 6.73 & 0.24 & 0.8 \\
\hline PSA & 0.95 & 50.45 & 5.04 & 0.9 & 0.8 \\
\hline SMO & 0.92 & 8.01 & 7.55 & 0.06 & 1.0 \\
\hline SPO & 0.93 & 20.93 & 7.5 & 0.64 & 1.5 \\
\hline SUM & 0.9 & 19.74 & 7.48 & 0.62 & 0.6 \\
\hline THD & 0.65 & 23.86 & 25.33 & -0.06 & 0.9 \\
\hline WIS & 0.78 & 17.85 & 21.26 & -0.19 & 1.1 \\
\hline HFM & 0.46 & 21.98 & 15.77 & 0.28 & 1.5 \\
\hline
\end{tabular}

\begin{tabular}{|c|c|c|c|c|c|}
\hline \multicolumn{6}{|c|}{$\mathrm{CO} 2$} \\
\hline station & $R E$ & $R M S E_{\text {prior }}^{\text {seas }}$ & $R M S E_{\text {post }}^{\text {seas }}$ & $R E^{\text {seas }}$ & $\chi^{2}$ \\
\hline ALT & 0.8 & 1.51 & 0.89 & 0.41 & 1.1 \\
\hline BRW & 0.75 & 1.16 & 0.89 & 0.23 & 1.1 \\
\hline CGO & 0.96 & 1.04 & 0.09 & 0.91 & 1.3 \\
\hline LEF & 0.54 & 2.48 & 3.2 & -0.29 & 0.5 \\
\hline MHD & 0.74 & 1.48 & 0.88 & 0.41 & 0.3 \\
\hline MLO & 0.78 & 0.74 & 1.11 & -0.5 & 0.1 \\
\hline NWR & 0.61 & 2.58 & 2.15 & 0.17 & 1.6 \\
\hline PSA & 0.96 & 0.25 & 0.1 & 0.6 & 1.0 \\
\hline SMO & 0.93 & 0.27 & 0.21 & 0.22 & 0.5 \\
\hline SPO & 0.98 & 0.21 & 0.05 & 0.76 & 0.4 \\
\hline SUM & 0.8 & 1.58 & 0.85 & 0.46 & 1.4 \\
\hline THD & 0.33 & 2.13 & 1.39 & 0.35 & 1.1 \\
\hline WIS & 0.6 & 2.36 & 1.61 & 0.32 & 0.6 \\
\hline
\end{tabular}

Table 5. Column "RE" presents the fractional reduction of the model vs. assimilated measurement RMSE (1- $\left.\frac{R M S E_{\text {post }}}{R M S E_{\text {prior }}}\right)$. Column "RMSE $E_{\text {prior }}^{\text {seas }}$ presents the RMSE of the a priori detrended time series compared to the assimilated measurement time series. Column "RMSE $E_{\text {post }}^{\text {seas }}$ presents the RMSE of the a posteriori detrended time series. Column " $R E^{\text {seas }}$ " presents the reduction of uncertainties using

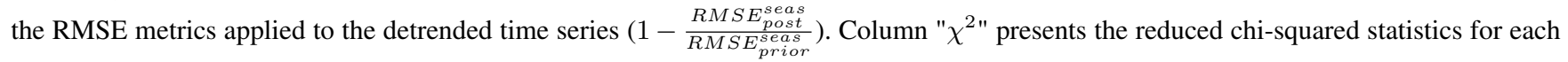
station. The detrended curves have been filtered to remove the synoptic variability (see Sect. 2.6). All statistics are for the period $2009-2019$.

equals to 1.04 , a value consistent with a fair configuration. The relative contribution of the measurement term to the total $\chi^{2}$ (Equation 3 or cost function at its minimum) is much larger than that of the flux term ( $80 \%$ versus $20 \%$ on average), suggesting that the a priori constraint is rather loose.

In addition to the global consistency between data errors and a priori flux errors, the validity of the relative weights (inverse 5 of the squared data error) assumed for the individual measurement residuals (i.e., at each station) is assessed (see Section 10). To this end, Table 5 shows the $\chi^{2}$ per station. The value is less than 1 for seven stations out of 15 for both compounds, meaning that the residuals are within the range of the assigned observation uncertainty. Among the stations with $\chi^{2}$ values greater than 1, HFM stands out and likely have too low uncertainties.

In order to better visualize the improvement on the seasonal cycle, we compare in Figure 5 the simulated a priori and a posteriori concentrations against observations at three sites: BRW, NWR and LEF. These time series have been detrended beforehand to retain the seasonal cycle. At BRW, the inversion has corrected the too low seasonal amplitude and the phase lag in the a priori concentrations within the range of observation uncertainties. At LEF, the a priori concentrations were already in good agreement with the observations and the inversion has not improved the simulated concentrations much. However, at 
NWR, the inversion struggles to correct the advanced phase, especially in the $\mathrm{CO}_{2}$ simulations, consistent with a $\chi^{2}$ greater than 1. One likely explanation is that our biome-scaling approach with one coefficient per PFT is too coarse to correct the spatial distribution of the prior fluxes, especially between relatively close sites such as NWR and LEF. The latter are more prone to be influenced by local fluxes than ocean stations such as MHD for example.
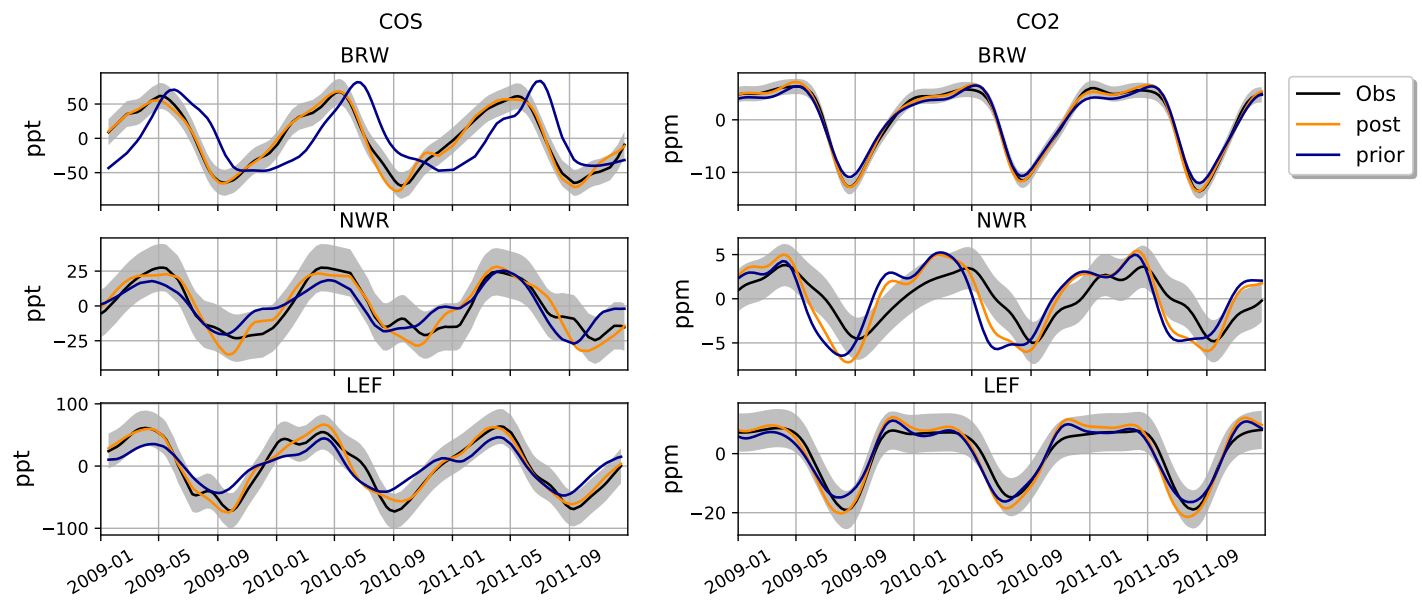

Figure 5. Detrended temporal evolutions of simulated and observed $\mathrm{CO}_{2}$ and $\mathrm{COS}$ concentrations at three selected sites, for the a priori and a posteri fluxes, simulated between 2009 and 2011. Top: Barrow station (BRW, Alaska, USA), middle: Niwot Ridge (NWR, USA) bottom: Park Falls (LEF, USA). The curves have been detrended beforehand and filtered to remove the synoptic variability (see Sect. 2.6).

\section{$5 \quad 3.2$ Optimized fluxes}

Table 6 summarizes our top-down assessment of the $\mathrm{COS}$ and the $\mathrm{CO}_{2}$ budgets. The inversion doubled the COS oceanic emissions to $530 \mathrm{GgS}_{\mathrm{yr}}{ }^{-1}$. Given the missing source in the reference fluxes, the ocean dominance in the measurement footprints, and the efficient reduction of the global error by $90 \%$, the increase of oceanic emissions is an expected behaviour of the Bayesian inverse system. In contrast, the inversion marginally decreased the total soil and vegetation absorption likely due to the seasonal constraints. Following a decrease of $7 \mathrm{GtC}_{\mathrm{yr}}{ }^{-1}$ of the GPP to match the COS constraint, the respiration has decreased by $10 \mathrm{GtC} \cdot \mathrm{yr}^{-1}$ in order to keep a land carbon sink in agreement with the global atmospheric $\mathrm{CO}_{2}$ budget. Thus, on a global scale, the inversion seems to have corrected the overestimated prior atmospheric trend by a larger decrease in respiration than in GPP. All residuals between the total prior and the posterior fluxes are within the assumed 1-sigma range of the prior uncertainty, except for respiration, where the increment is twice as large as the standard deviation. The residuals are even much smaller than the prior standard deviation for the anthropogenic and the biomass burning emissions, suggesting that we could have narrowed the initial errors for those components.

The total oceanic COS emission remains lower than previous top-down studies using different configurations and observations, which instead estimated an oceanic source between 700 and $1000{\mathrm{GgS} . \mathrm{yr}^{-1}}^{-1}$ (Berry et al., 2013a; Kuai et al., 2015a; 
Launois et al., 2015b). Several reasons could explain these differences. First, we assimilated continental surface measurements from the NOAA network through the whole years of 2008-2019 while Kuai et al. (2015a) assimilated a single month of satellite retrievals over the tropical oceans. Second, the Zumkehr et al. (2018) anthropogenic emissions are much higher than the Kettle et al. (2002) one used in these previous studies. Finally, the prior biospheric and oceanic fluxes used, especially over the tropical domain which is poorly constrained in the inversion, could explain the differences with the previous COS budgets. Launois et al. (2015b) noticed a dependence between the magnitude of the optimized ocean source and the prior vegetation uptake. The larger biospheric sink used in Launois et al. (2015b); Berry et al. (2013a) requires a larger oceanic source over the tropics to close the COS budget. This is particularly true for Berry et al. (2013a) who used a fixed large biospheric sink of 1100 GgS.yr ${ }^{-1}$.

\begin{tabular}{|c|c|c|}
\hline \multicolumn{3}{|c|}{ COS fluxes $[\mathrm{GgS} / \mathrm{y}]$} \\
\hline Source & Prior & Post \\
\hline Anthropogenic emissions & $398.3 \pm 217.2$ & $327.2 \pm 26.3$ \\
\hline Biomass burning emissions & $53.3 \pm 30.8$ & $65.1 \pm 24.2$ \\
\hline GPP & $-656.8 \pm 30.4$ & $-619.5 \pm 19.0$ \\
\hline Oceanic emissions & $269.3 \pm 355.3$ & $526.4 \pm 37.2$ \\
\hline Atmospheric OH sink & $-100.0 \pm 0.0$ & $-100.0 \pm 0.0$ \\
\hline Soil fluxes & $-236.1 \pm 19.8$ & $-209.0 \pm 16.7$ \\
\hline
\end{tabular}

\begin{tabular}{|c|c|c|}
\hline \multicolumn{3}{|c|}{ CO2 fluxes $[\mathrm{GtC} / \mathrm{y}]$} \\
\hline Source & Prior & Post \\
\hline Biomass burning emissions & $1.9 \pm 0.0$ & $1.9 \pm 0.0$ \\
\hline Fossil fuel emissions & $9.6 \pm 0.0$ & $9.6 \pm 0.0$ \\
GPP & $-126.7 \pm 5.2$ & $-119.8 \pm 3.3$ \\
\hline Oceanic fluxes & $-1.9 \pm 0.0$ & $-1.9 \pm 0.0$ \\
\hline Respiration & $124.6 \pm 5.0$ & $115.1 \pm 3.3$ \\
\hline
\end{tabular}

Table 6. Prior and posterior total fluxes and their associated 1-sigma uncertainty as part of the COS (left) and the $\mathrm{CO}_{2}$ (right) budgets. The mean magnitude of the different types of fluxes is given for the period 2009-2019. The vegetation sink is computed from the vegetation

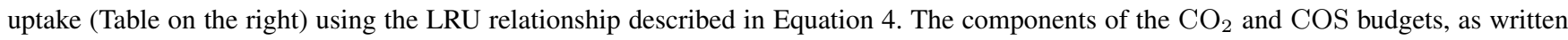
here, have been obtained by adding all the related optimized parameters (see Table 3 for a description of the parameters). The flux convention is positive upwards (from the surface to the atmosphere). For a given component, the associated uncertainty is the root-mean square of the sum of all the posterior error covariance terms related to the component divided by the number of years (11 here).

Figure 6 represents the zonal mean of the prior and posterior oceanic and continental COS fluxes as a function of latitude. The inversion increased ocean fluxes over the tropics while decreasing them in the high latitudes. This behaviour was already noticed by Berry et al. (2013a) who used a different inverse system and the Kettle et al. (2002) oceanic flux as a prior. Over the tropics, $\mathrm{COS}$ and $\mathrm{CS}_{2}$ measurements in sea waters do not support this increase as already mentioned in the introduction (Lennartz et al., 2017, 2020a). However, COS emissions through DMS oxydation in pristine marine environment, could play a role in sustaining this tropical source. Over the northern and southern oceans, high emissions in our reference oceanic flux from Lennartz et al. (2017) mainly arise from the direct oceanic emissions (see Fig. 3). The latter could be overestimated: the COS concentrations simulated by the ocean box model are higher than most of the measurements made in sea waters sampled over different parts of the globe (Lennartz et al., 2017). This remark supports the inversion decrease of the oceanic emissions over the mid and high latitudes. The decrease beyond $50^{\circ}$ towards the poles also reflects a seasonal cycle in COS sea water concentrations of a much lower amplitude than the one in atmospheric COS in the marine boundary layer (Lennartz et al., 
2020b). This strong marine seasonal cycle is not attenuated enough by mixing processes within the boundary layer and the inversion weakened the oceanic release to match the seasonal cycle in atmospheric COS concentrations at BRW and ALT. In particular, the emissions in the northern high latitudes have been suppressed in summer to correct the late peak in the time series at BRW on Figure 5. While oceanic emissions decrease in the high latitudes, the terrestrial sink tends to increase. The change in terrestrial sink is mainly attributed to vegetation (see Fig. S3). The change in soil fluxes goes in the same direction than the change in COS vegetation uptake.

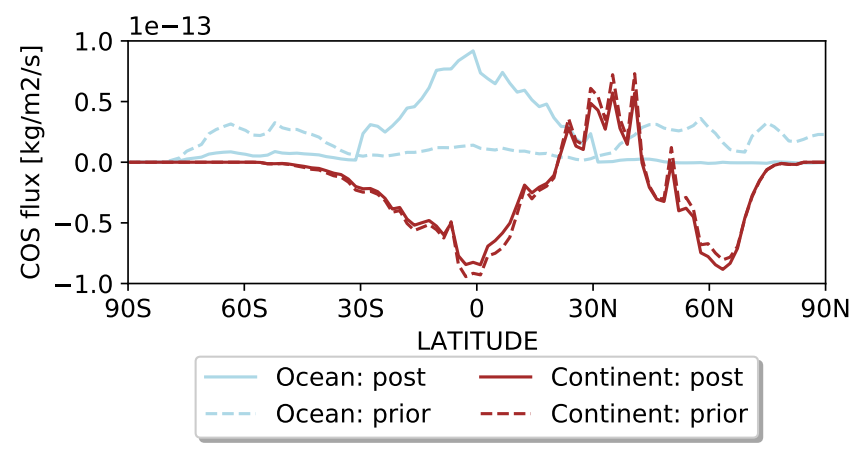

Figure 6. Latitudinal distribution of the prior (dashed line) and posterior fluxes (full line) for the continental (brown) and oceanic components (blue) of the COS budget. The fluxes have been averaged for the years 2009-2019.

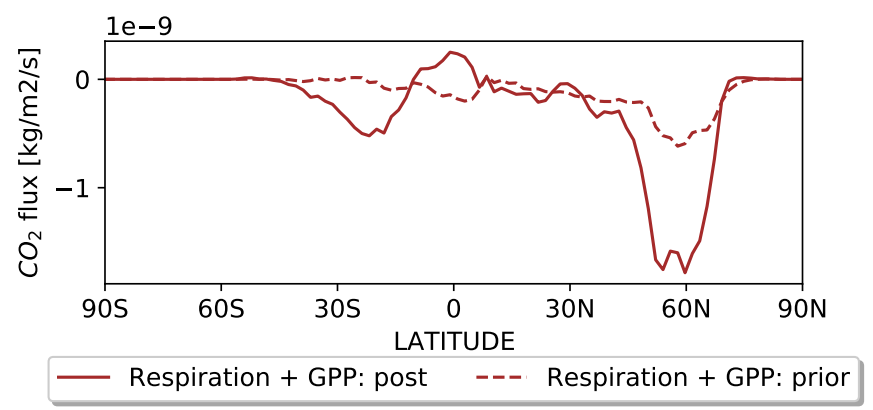

Figure 7. Latitudinal distribution of the prior (dashed line) and posterior net $\mathrm{CO}_{2}$ fluxes from the terrestrial vegetation (full line). Vegetation fluxes are the sum of GPP and respiration fluxes. The fluxes have been averaged for the years 2009-2019.

Regarding the impact on the $\mathrm{CO}_{2}$ budget, Figure 7 shows the latitudinal distribution of the net $\mathrm{CO}_{2}$ vegetation fluxes defined as the sum of respiration and GPP before and after inversion. The inversion has increased almost threefold the net vegetation absorption above $50^{\circ} \mathrm{N}$. This response is a common feature of the current inverse systems which, by assimilating $\mathrm{CO}_{2}$ measurements only into an atmospheric transport model, infer a higher net vegetation sink in the high latitudes than land-surface models. Indeed, in Fig. 8 of Friedlingstein et al. (2020), the net land sink (above $30^{\circ}$ ) given by the average of 17 process models is between $0.5 \mathrm{GtC} / \mathrm{y}$ and $1.5 \mathrm{GtC} / \mathrm{y}$ whereas the one given by 6 inverse systems is between 1 and 2.5 
GtC/y averaged over the last ten years. More specifically, Figure 8 illustrates how the inversion changes the seasonal cycle of GPP and respiration within each of the 15 PFTs of the ORCHIDEE model. The changes in the global total per PFT are shown separately in the Supplementary (see Fig. S3). In the tropics within PFTs 2 and 3 (Tropical Broad-leaved Evergreen and Raingreen Forests, see Table 1), the inversion decreased GPP by about 4 GtC.y ${ }^{-1}$ whereas respiration lost 1 GtC.yr ${ }^{-1}$, leading to a small source of $\mathrm{CO}_{2}$ In the mid-latitudes (PFTs 4, 5 and 10, Table 1), the inversion weakened GPP and respiration by 5 GtC.yr ${ }^{-1}$ and 2 GtC.yr ${ }^{-1}$, respectively. The second salient change is an increase in $\mathrm{CO}_{2}$ absorption within the high latitudes covered by PFTs 7, 8, 9 and 10 (see Table 1). Indeed, GPP increased by almost 2 GtC. ${ }^{-1}$ while respiration only decreased by 0.2 GtC.yr ${ }^{-1}$ in total. The increased GPP over the boreal latitudes explains the higher seasonal cycle of the a posteriori COS and $\mathrm{CO}_{2}$ concentrations at sites BRW and ALT. The comparison of GPP and respiration from ORCHIDEE against eddy covariance measurements at several sites around the globe pointed at an underestimation of these components, consistent with our inversion results (not shown). A complete validation of this ORCHIDEE version will be the topic of a future publication.

\subsection{Comparison with independent observations}

\subsubsection{Evaluating the seasonal cycle with SIF data}

In order to assess the realism of the a posteriori GPP, its seasonal cycle is compared with the one of the SIF from the GOME-2 product. Although the ecosystem-dependant bias in the SIF products makes a direct comparison with GPP impossible, SIF has been recognized as an good indicator of the GPP temporal dynamic. Figure 8 superimposed the minimum of the SIF on the GPP seasonal cycle. The normalized SIF seasonal cycle is further shown on Fig. S5. Ideally, the minimum coincides with the minimum of the GPP seasonal cycle. Overall, the inversion has not altered the timing of the COS seasonal depletion. The seasonal cycle is degraded within the PFT 2 (Tropical Broadleaved Evergreen), PFT 3 (Tropical Boreal Raingreen Forest) and PFT 14 (Tropical $\mathrm{C} 3$ grass), questioning the realism of a weaker $\mathrm{CO}_{2}$ and COS absorption over the tropics. Within the PFT 2 , the inversion tends to produce a seasonal signal in opposition of phase with the SIF. In the mid-latitudes, the seasonal phase of the GPP is slightly degraded within PFT 4 (Temperate Needle-leaved Evergreen Forest) while it is improved within PFT 12 (C3 Agricultural Land). In the high latitudes, the phase of the seasonal cycle, which was in quite good agreement with the SIF in the GPP a priori, has been altered by the inversion.

\subsubsection{Comparison with independent atmospheric observations}

As a second step, we assess the a posteriori concentrations using several datasets : the MIPAS satellite retrievals, the HIPPO airborne measurements and the surface measurements over Japan and France (see section 2.2). In particular, the MIPAS retrievals of COS atmospheric concentrations at $250 \mathrm{hPa}$ in the tropics give insight into the magnitude of the main biospheric sink located over Brazil during the wet season, when convective air masses reach the upper troposphere (Glatthor et al., 2017). First, Figure 9 shows the a posteriori and a priori COS seasonal concentrations at $250 \mathrm{hPa}$, convolved with the MIPAS averaging kernels and averaged over the period 2009-2012. We see that the inversion reduced the RMSE by more than one third 
a) GPP
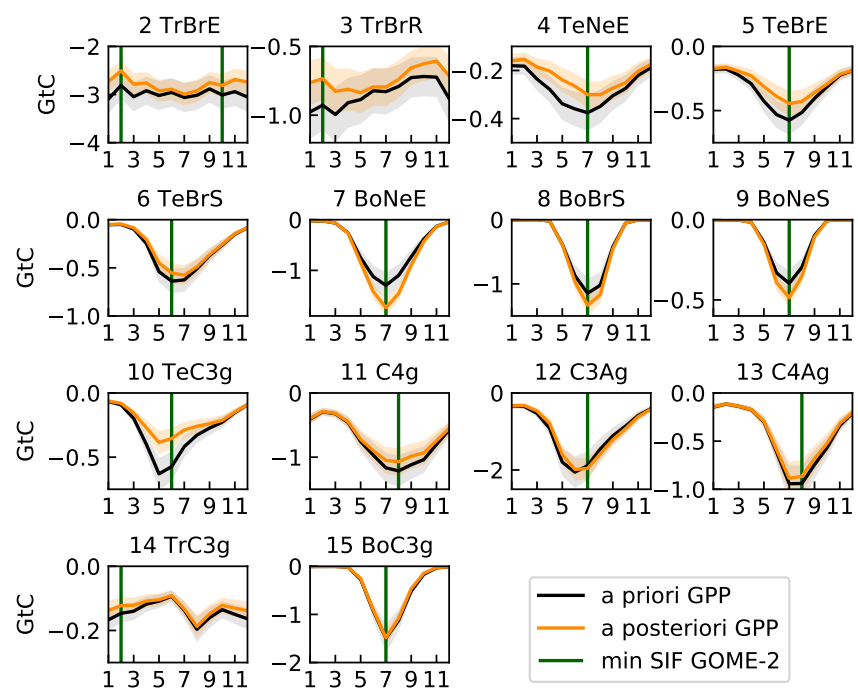
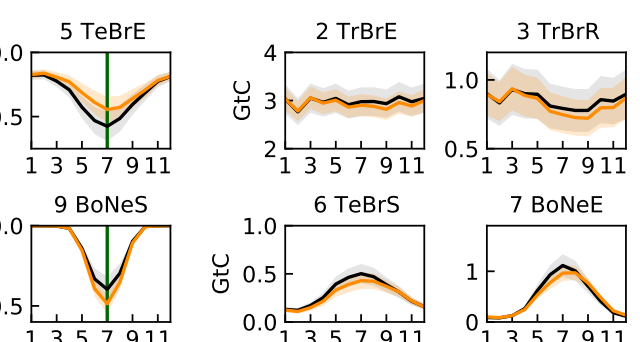

b) Respiration
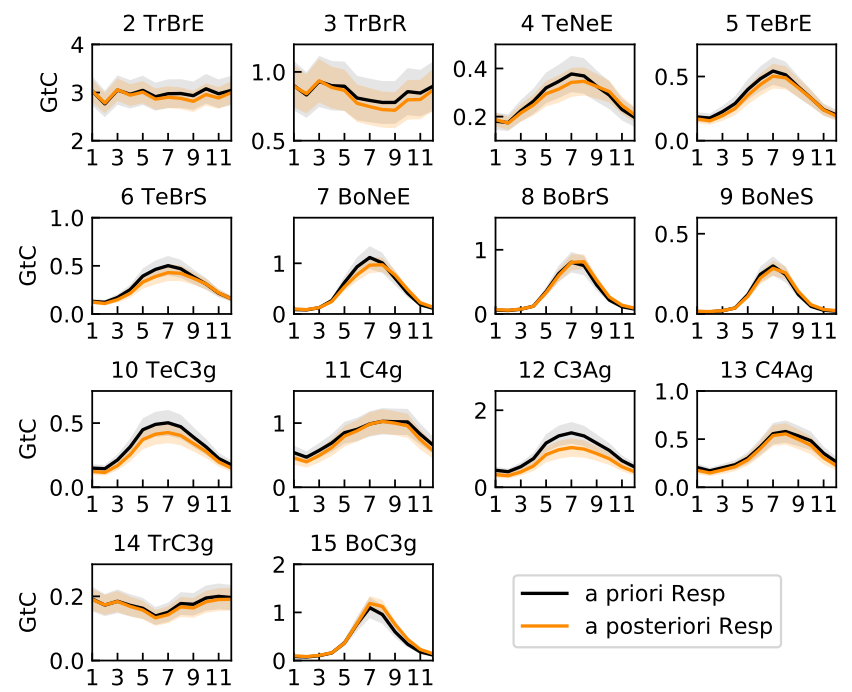

\begin{tabular}{|c|c|c|c|c|c|c|c|c|c|c|c|c|c|c|}
\hline & TrBrE & TrBrR & TeNeE & TeBrE & TeBrS & BoNeE & BoBrS & BoNeS & TeC3g & $\mathrm{C} 4 \mathrm{~g}$ & $\operatorname{TrC} 3 \mathrm{Ag}$ & $\mathrm{C} 4 \mathrm{Ag}$ & $\operatorname{TrC} 3 \mathrm{~g}$ & BoC3g \\
\hline Prior & -0.3 & 0.5 & 1.0 & 1.0 & 1.0 & 1.0 & 1.0 & 1.0 & 0.9 & 0.9 & 1.0 & 0.9 & 0.8 & 1.0 \\
\hline Posterior & -0.8 & 0.1 & 0.9 & 1.0 & 1.0 & 1.0 & 1.0 & 1.0 & 0.9 & 0.9 & 1.0 & 1.0 & 0.6 & 1.0 \\
\hline
\end{tabular}

Figure 8. Mean seasonal cycle of the total prior (black) and posterior (orange) GPP (a) and respiration (b) fluxes and their uncertainties within each of the 15 PFTs during the period 2009-2018. The minimum of the mean seasonal cycle of the SIF from GOME-2 has been superimposed on the GPP seasonal cycle in green. The fluxes have been averaged between 2009-2018. Below are the correlation coefficient between the monthly SIF an the GPP averaged during the period 2009-2018. The values in bold indicate the PFTs with a GPP improved or unchanged by the inversion. PFT 1, the bare soil, is not shown as respiration and GPP are null. Only the values integrated over the Northern Hemisphere are shown for PFTs 4, 5, 6, 10,11, 12 and 13. The identifiers of the PFTs are described in Table 1. The acronyms Tr, Bo and Te mean Tropical, Boreal and Temperate, respectively.

throughout the whole year. The inversion removed the positive bias above $50^{\circ} \mathrm{N}$ in DJF and under $50^{\circ} \mathrm{N}$ in MAM (as a result of lower oceanic emissions in the high latitudes) and the negative bias over the tropical oceans (as a result of higher tropical oceanic emissions). Such an increase is consistent with Glatthor et al. (2015), who also needed to multiply the vegetation sink and the oceanic sources from Kettle et al. (2002) by 4 to better match the MIPAS retrievals. However, there are some remaining deficiencies. In particular, the COS depletion observed between Brazil and Africa is well reproduced but its amplitude is slightly underestimated. The simulated COS concentrations are also too weak in the Pacific Ocean. The reasons could be an underestimation of the tropical emissions or a too homogeneous distribution of these emissions through the longitudes. We have to remember that we have optimized a single factor for the oceanic emissions over the whole tropical band and thus the spatial gradients within the tropical band have not been optimized. This could explain the lack of variability over the ocean. Over the mid-latitudes, the weaker concentrations in spring point at a too weak terrestrial sink or too strong oceanic emissions. 
The lack of stratospheric COS loss could also be responsible for these underestimated concentrations since they are close to the tropopause near $60^{\circ}$.

a) MIPAS
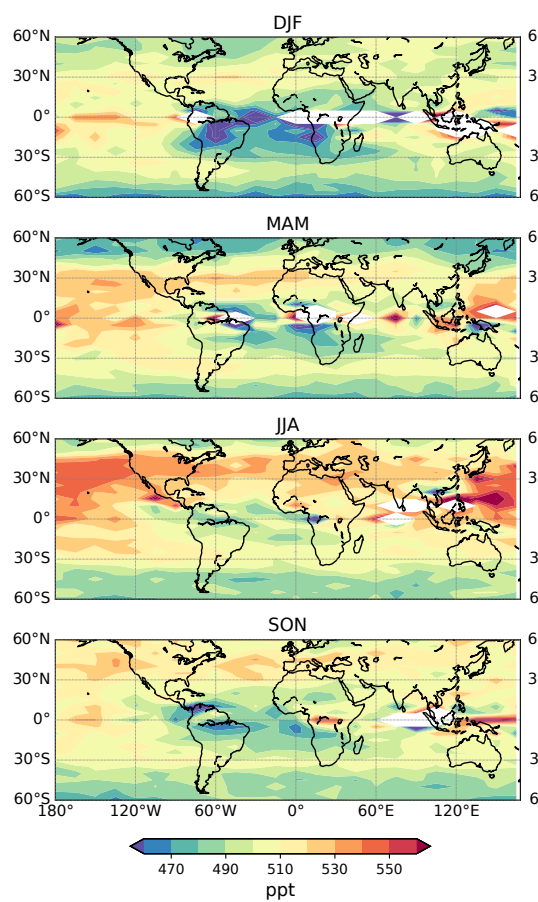

b) Prior concentrations

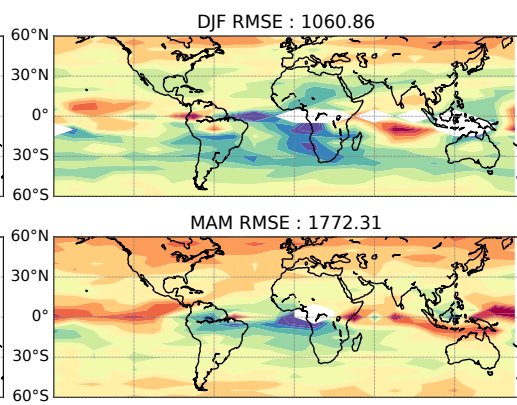

JJA RMSE : 844.13

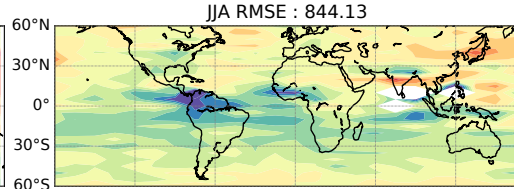

SON RMSE : 914.09

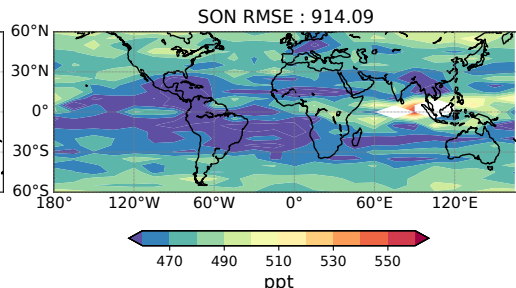

C) Posterior concentrations
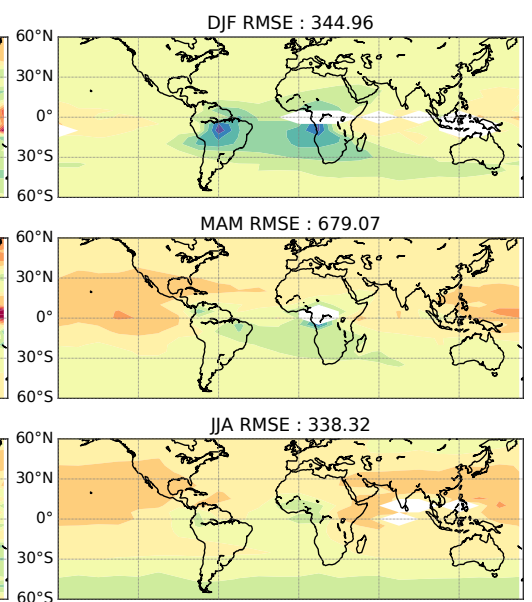

SON RMSE : 240.79

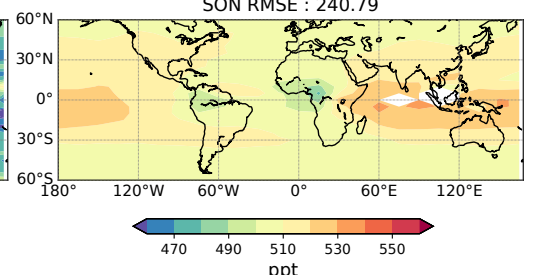

Figure 9. Climatological seasonal COS distributions at $250 \mathrm{hPa}$ measured by (left column) MIPAS and simulated using the prior scenario (middle column) and (right column) the optimized scenario. The data sets cover the years 2008-2012, and the displayed seasons are (top row) December to February, (second row) March to May, (third row) June to August, and (fourth row) September to November. White areas are data gaps, and dark blue COS amounts above the Amazonian region bottom left) are below 450 pptv. The negative bias in the prior concentrations, which results from the unbalanced COS prior budget, has been removed on panel c.[FC: a justifer, pas clair]

We further assess the latitudinal distribution of the COS sources and sinks given by the inversion with the help of the HIPPO airborne measurements. For this purpose, Figure 10 compares the inter-hemispheric gradient in the a posteriori and a priori $\mathrm{COS}$ and $\mathrm{CO}_{2}$ concentrations against the HIPPO airborne measurements. We have verified beforehand that the transport model performs well at sites LEF and THD (see Fig. S6) whose continental and coastal locations respectively emphasize transport errors. The representation of vertical mixing is indeed crucial for continental sites (Geels et al., 2007) such as LEF whereas coastal sites such as THD are difficult to represent in coarse resolution models (Riley et al., 2005). Given the good agreement between modelled and observed vertical profile at these two sites (see Fig. S6), transport errors are assumed here to be of secondary importance compared to the uncertainty in the fluxes and differences between the concentrations apriori and aposteriori are ascribed to differences in the surface fluxes. Figure 10 shows that the a posteriori better matches the observed latitudinal distribution. Especially, the shared positive bias in the northern latitudes between $\mathrm{COS}$ and $\mathrm{CO}_{2}$ has been corrected 
as a result of higher GPP. The improvement is also noticeable in the $\mathrm{COS}$ and $\mathrm{CO}_{2}$ vertical profiles over Northern America (see Supplementary material). In contrast to the Ma et al. (2021) top-down study, there is no significant negative bias in the COS vertical profiles here (see Fig. S6-10).

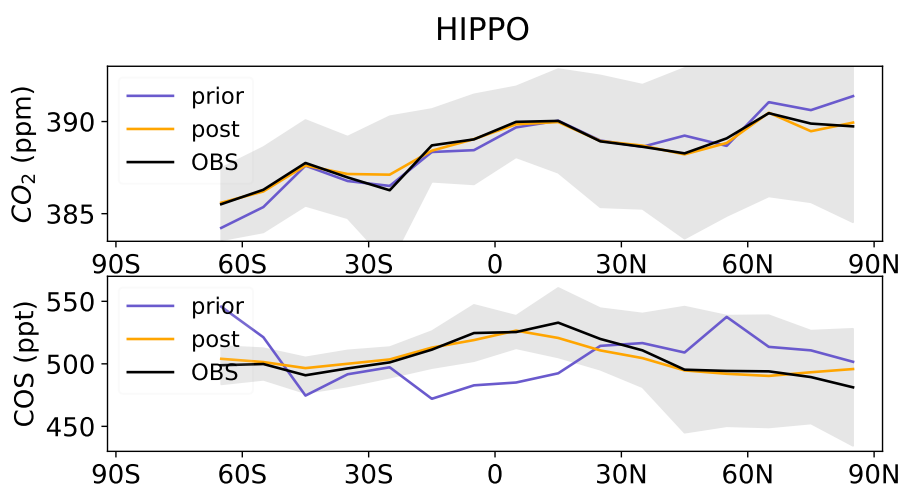

Figure 10. Comparison of the latitudinal variations of the a priori and a posteriori LMDz COS abundance with the HIPPO observations. The LMDz COS abundances have been vertically shifted such that the means of the a priori are the same as the mean of the HIPPO data (521 ppt). The error bar is calculated as the standard variation of the averaged COS concentration.

The optimized COS fluxes are now assessed at three surface sites in Japan : Miyakojima (MIY; $24^{\circ} 80 \mathrm{~N}, 125^{\circ} 27 \mathrm{E}$ ), Yokohama (YOK; $35^{\circ} 51 \mathrm{~N}, 139^{\circ} 48 \mathrm{E}$ ), and Otaru (OTA; $\left.43^{\circ} 14 \mathrm{~N}, 141^{\circ} 16 \mathrm{E}\right)$. In winter, these sites sample air masses coming from the eastern northern edge of China (see Hattori et al. (2020) and the LMDz footprints on Fig. S11). The confrontation of the posterior concentrations against measurements serves at evaluating the spatial distribution of the Zumkehr et al. (2018) anthropogenic inventory over the eastern part of China. In Figure $11 \mathrm{a}$ and b, we show a comparison between the a posteriori and observed COS concentrations at each of the three sites for both winter and summer 2019. The averaged COS surface concentrations during February-March 2019 and July-August 2019 are also shown in Figure 11. At the northernmost site OTA, the overestimation of the COS concentrations of $40 \mathrm{ppt}$ points at too strong anthropogenic sources in Northern China in the modified Zumkehr et al. (2018) inventory. The site located in middle Japan, YOK, has a simulated concentration of almost 100 ppt higher than the one observed. This implies an error in the inventory which indicates a source above the site (see Figure S9). As for the southern site MIY, the model underestimates the COS concentration by $100 \mathrm{ppt}$, pointing at an underestimation of the anthropogenic sources over the eastern edge of China or Korea.

In summer, sites YOK and OTA sample air masses coming both from continental Japan and from the Pacific Ocean at the East of Japan. The southernmost site MIY seems to be mostly affected by oceanic sources originating from the east (see the LMDz footprints on Figure S8). The sites OTA and YOK overestimate the COS concentrations by 60 and 150 ppt and reflect the influence of the misplaced anthropogenic source in center Japan (Figure S10). At MIY, the comparison with observations suggests that the oceanic source is too strong because the atmospheric concentrations are overestimated by 40 ppt in southern Asia and in northern Japan. However, the oceanic source may not be overestimated in Southern Asia because we have assumed 
that $\mathrm{CS}_{2}$ is emitted as COS. Ma et al. (2021) showed that implementing the $\mathrm{CS}_{2}$ oxidation process into the atmosphere leads to a decrease in surface COS concentrations of $40 \mathrm{ppt}$ in the vicinity of Japan. Also, there is an oceanic hot spot located in the footprint of the site (see Figure S9) which might not be reliable.

The spatial pattern of the Zumkehr et al. (2018) inventory seems to show too strong sources over Japan and too weak sources 5 in the eastern edge of China. The inversion system could therefore have compensated the lack of anthropogenic source in the eastern part of China by increasing the oceanic source. However, it is difficult to extrapolate conclusions drawn from a specific region to a larger scale. There is also no clear indication that the oceanic sources are overestimated eastward of Japan.

Finally, we perform a similar assessment of the optimized COS fluxes in winter at station GIF in France. The footprint of the station covers central France and countries at the eastern edge such as Belgium and the eastern part of Switzerland (see Figure S13). The confrontation of the posterior concentrations against measurements serves at evaluating the Zumkehr et al. (2018) anthropogenic inventory and, in particular, its spatial distribution over central France since the terrestrial sink is assumed to be much smaller and that the oxidation rate is low during this period of the year. Station MHD provides very low constraints over France and Eastern Europe as its footprint is mainly oceanic. The comparison between the posterior concentrations and atmospheric measurements on Figure 11c indicates that the anthropogenic sources within the footprint of the station are also overestimated: the a posteriori concentrations are more than $130 \mathrm{ppt}$ higher than the one observed. This confirms the study of Belviso et al. (2020) which reported a misplaced hot-spot on Paris (see Fig. S14). In reality, the concentrations at GIF are 10 ppt lower than the one at the background MHD, reflecting a dominant influence of the biospheric sink.

\section{Discussion and perspectives}

The lack of continuous in-situ observations, especially over the tropics, limits our capacity to infer the COS surface fluxes by inverse modelling and therefore to optimize GPP. There is some hope that new satellite products could address this issue but at this stage, current COS retrievals have also their limitations such as, for instance, cloud interference or the lack of sensitivity to the surface fluxes (Glatthor et al., 2017; Kuai et al., 2015b; Vincent and Dudhia, 2017). Letting aside this obvious lack of observations to be assimilated, we are now discussing the way forward to improve our knowledge of the COS budget.

- Improving the anthropogenic inventory The inverse system has weaken the global anthropogenic source by almost $20 \%$. It is unclear whether this decrease results from an overestimation of the global emissions or from misplaced hotspots within the footprints of the assimilated stations. For instance, the overestimated concentrations in the model at a site located in middle Japan point at a misplaced hot-spot in the vicinity of the station. If these measurements were assimilated, the inverse system would tend to produce an unrealistic negative flux increment over the area to match the observed concentrations. A similar inconsistency has been reported between measurements at the Gif-sur-Yvette background site and the hot-spot to the north, over Paris, stated in the Zumkehr et al. (2018) inventory (Belviso et al., 2020). Thus, the reported hot spot locations and magnitudes must be improved to be able to benefit from these new observations at Gif-Sur-Yvette and in Japan. More generally, the disagreement between simulated and observed COS concentrations tested at these sites indicated that there is a large uncertainty in this inventory. Further work first includes 

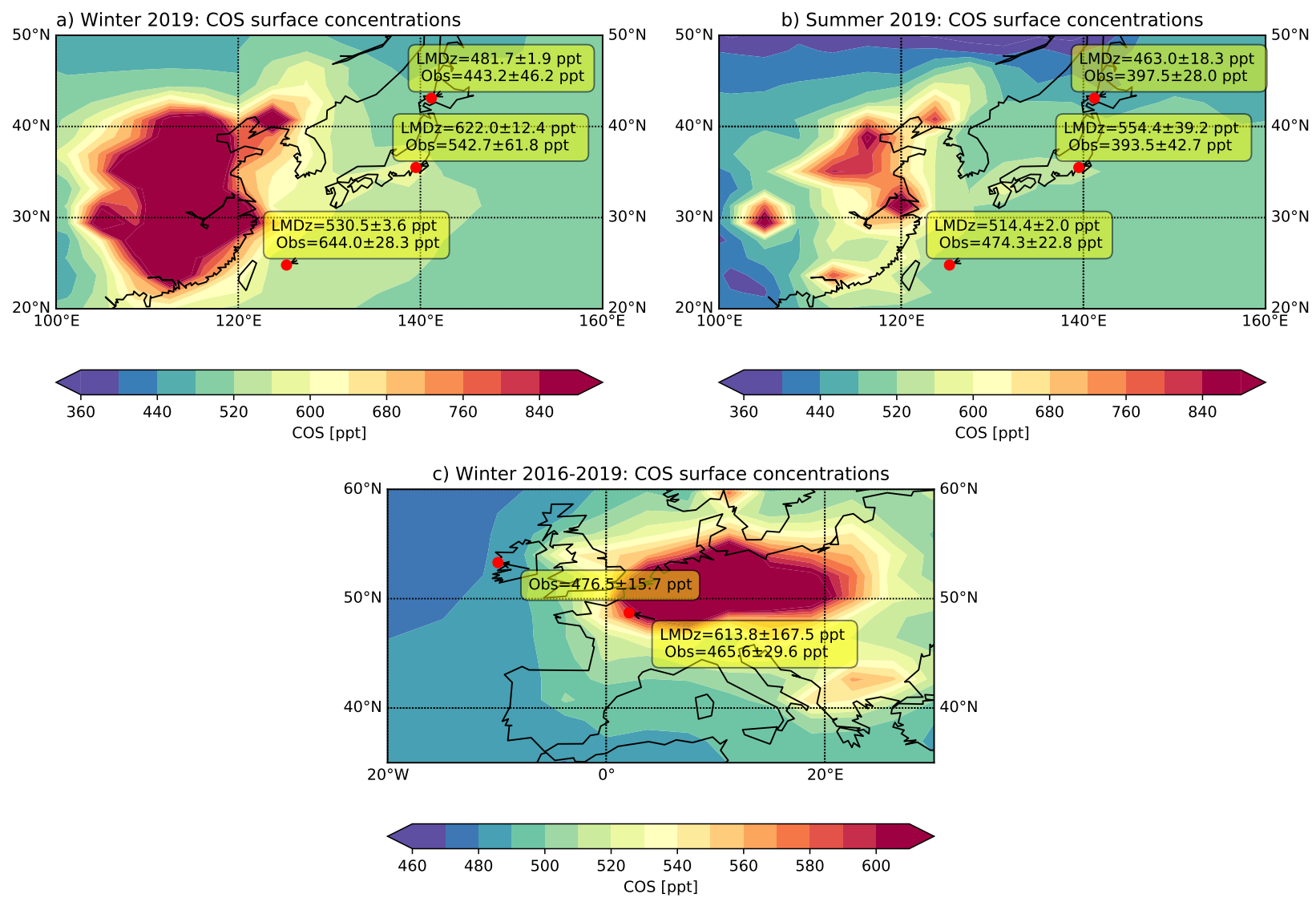

Figure 11. Mean COS concentration sampled at the first level of the LMDz model in a) winter 2019 (February March) , b) in summer 2019 (July-August) and c) in winter (Dec-Feb) during the period 2016-2019. The values within the yellow frames correspond to the mean COS observed and modelled COS concentrations, and their standard deviation at four surface sites: Miyakojima $\left(24^{\circ} 80 \mathrm{~N}, 125^{\circ} 27 \mathrm{E}\right)$, Yokohama $\left(35^{\circ} 51 \mathrm{~N}, 139^{\circ} 48 \mathrm{E}\right)$, and Otaru $\left(43^{\circ} 14 \mathrm{~N}, 141^{\circ} 16 \mathrm{E}\right)$ and GIF $\left(48^{\circ} 42^{\prime} \mathrm{N}-2^{\circ} 08^{\prime} \mathrm{E}\right)$. Station MHD has been assimilated and is shown here as a reference.

a more thorough evaluation of European anthropogenic sources using COS retrievals from IASI (Serio et al., 2020) and from Fourier transform infrared spectrometry (Wang et al., 2016; Krysztofiak et al., 2015) along with a chemical transport model in order to correct their spatial distribution.

- Improving the relationship between COS plant uptake and GPP For the LRU values, we have only made a distinction between C4 and C3 plants. We plan to include the PFT dependence of the LRU by using the LRU dataset of Maignan et al. (2020) derived from a mechanistic vegetation model, and for which conductances will be further tuned with eddycovariance flux measurements. LRU absolute values are indeed critical. For instance, if the LRU were larger at high latitude, the inversion would not need to increase the GPP as much. However, LRUs have been estimated to be lower in the boreal ecosystems (around 1 and 1.8 for Maignan et al. (2020) and Seibt et al. (2010) respectively) than in the tropical 
and temperate ecosystems (around 1.3 and 3 for Maignan et al. (2020) and Seibt et al. (2010) respectively). So, using another existing LRU dataset will likely lead to a comparable GPP sink in the high latitudes. Another simplification of our study is that the current LRU approach does not take into account the feedback between COS vegetation sink and atmospheric concentrations. The atmospheric concentrations vary on seasonal and interannual timescales but have been indeed considered constant per latitudinal band. Such a feedback might have significant impact on the total vegetation sink (see for example the discussion in Ma et al. (2021)), in particular over the Amazon. Thus, refining our inverse system would require including the feedback between the atmospheric concentrations and the COS vegetation sink (first order approach).

- Increasing the realism of the soil fluxes The GPP estimate strongly relies on the realism of the soil fluxes. The soil fluxes need to be more constrained and their errors better defined. In particular, more attention should be paid to the seasonality of soil fluxes compared to the one of the vegetation fluxes in the field measurements. For instance, this would help to know whether the two months-lag between the soil and vegetation fluxes in the high latitudes is realistic.

- Improving the prior COS oceanic fluxes with the help of an ocean model Prior oceanic emissions are probably overestimated in the high and mid latitudes as shown by Lennartz et al. (2017, 2020a) and as suggested by the inverse system. A possible reason could be the lack of horizontal transport and downward mixing within the water column in their ocean box model. Another estimation of the oceanic emissions based on an ocean general circulation and biogeochemistry model which fully represents the transport of water masses would help to better define the range of uncertainties of these emissions. In particular for DMS, it has been shown that, the use of the NEMO PISCES ocean model that accounts for nutrient dynamics, has resulted in higher emissions over most of oligotrophic subtropical zones compared to the Lana et al. (2011) (Belviso et al., 2012). In the past, direct oceanic emissions have been simulated in the Nucleus for European Modelling of the Ocean (NEMO) Pelagic Interaction Scheme for Carbon and Ecosystem Studies (PISCES) ocean model by Launois et al. (2015a) but the hydrolysis rate has later been found erroneous. Future work includes the correction of the rate in the NEMO-PISCES ocean model and also the implementation the oceanic physical processes responsible for the $\mathrm{CS}_{2}$ emissions. Moreover, the single factor used to convert DMS into COS is very uncertain and may not apply to any atmospheric conditions (Von Hobe, 2020, personnal communication). Since there is so much DMS emitted by the ocean (ca. 28 Teragrams per year), a small change in the conversion factor (e.g. from the current $0.7 \%$ to e.g. $2.5 \%$ ) could make a large difference.

- Implementing a complete chemistry of COS into the LMDz atmospheric transport model For an economy of computation time, we have assumed that the DMS and $\mathrm{CS}_{2}$ oxidation into COS happens instantly in the atmosphere. However, Ma et al. (2021) showed that such simplifications could modify the average COS surface concentrations up to 80 ppt outflow of the anthropogenic sources. These chemical reactions need be implemented in the LMDz atmospheric model in order to properly evaluate the Zumkehr et al. (2018) inventory with the help of COS atmospheric measurements. The lifetime of the DMS, $\mathrm{CS}_{2}$ and, to a lesser extent, COS into the atmosphere depends on the realism of the OH fields. Therefore, the impact of their uncertainty on the inverse results needs also to be quantified. Chemical transport models 
disagree on the spatial distribution of the $\mathrm{OH}$ fields and using other $\mathrm{OH}$ fields could significantly alter the COS budget as it was demonstrated for the methane budget (Zhao et al., 2020b, a). In addition, we plan to introduce the stratospheric chemistry of COS into the LMDz atmospheric transport model. The implementation of a complete chemistry while keeping a multi-year inversion window requires using a variational approach: the chemical reactions are indeed more difficult to implement in an analytical inverse system using pre-computed Jacobian matrices.

- Including potentially important missing sources For instance, we have neglected the contribution of volcanic emissions on the COS budget. As the locations and time of the volcanic eruptions are well known, emissions based on existing measurements (Belviso et al., 1986; Chiodini et al., 1991; Symonds et al., 1992; Sawyer et al., 2008; Notsu and Mori, 2010) could be mapped and given as an input to the atmospheric model. Likewise, DMS emissions from vegetation, tropical forests, soil and wetlands (Yi et al., 2008; Kanda et al., 1992; Minami et al., 1993) have not been included although their contribution to the total DMS release have been estimated in the past between 2 and $15 \%$ (Watts, 2000; Gondwe et al., 2003). Moreover, we have neglected the COS emissions from the anoxic soils that might be a part of the missing tropical source, in particular within the waterlogged soils of the rice paddies (Yi et al., 2008).

\section{Conclusion}

We have developed an analytical system that optimizes GPP, plant respiration $\mathrm{CO}_{2}$ flux and COS soil fluxes within the 15 PFTs defined in the ORCHIDEE terrestrial model, enabling to take into account the ecosystem-dependence of the fluxes. The LRU approach was used to link the GPP to the COS plant uptake. With this system, we have performed a joint assimilation of $\mathrm{CO}_{2}$ and $\mathrm{COS}$ atmospheric measurements into the LMDz atmospheric transport model for the period 2008-2019. From a technical point of view, the inverse system is able to find the components of the $\mathrm{CO}_{2}$ and $\mathrm{COS}$ budgets that give a good fit

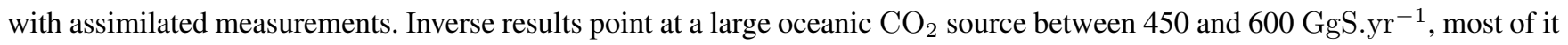
located in the tropics. The inversion leads to a GPP increase of a few GtC in the high latitudes and a decrease in the same order of magnitude in lower latitudes (tropics and mid-latitudes) compared to the initial prior estimates from the ORCHIDEE LSM. For COS, this means a vegetation sink of around $-620 \mathrm{GgS}_{\mathrm{yr}}{ }^{-1}$, which is in the lower range of recent estimates based on topdown approaches (Launois et al. (2015b): -663-772 GgS.yr ${ }^{-1}$, Ma et al. (2021): 557-1053 GgS.yr ${ }^{-1}$ ). The soil sink and the

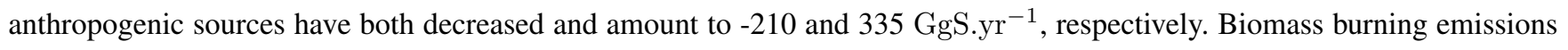
have been slightly revised upward to $65 \mathrm{GgS}_{\mathrm{yr}}{ }^{-1}$. Compared to GPP, plant respiration has almost not been affected in the high latitudes whereas its total value has decreased by only one quarter of the change in GPP in lower latitudes. The resulting $\mathrm{CO}_{2}$ biospheric fluxes, defined here as the sum of the respiration and GPP, has lost $2 \mathrm{GtC}_{\mathrm{yr}}{ }^{-1}$ above $30^{\circ} \mathrm{N}$ compared to the prior fluxes simulated by the ORCHIDEE LSM. This behaviour is shared by current inverse systems which infer the net $\mathrm{CO}_{2}$ fluxes from atmospheric $\mathrm{CO}_{2}$ measurements (Friedlingstein et al., 2020).

Several aspects of the inferred COS fluxes, such as the inter hemispheric gradient, the tropical spatial distribution, the anthropogenic emissions over Japan, China and France, were evaluated with independent atmospheric measurements over different parts of the globe. In the tropics, independent observations of the upper-troposphere COS partial column and the SIF 
weaken our confidence in the change in tropical GPP; the inverse system actually lacks measurements in this area to ensure a robust partitioning between the oceanic and the continental components of the COS budget. Indeed, the footprint map of the assimilated measurements indicates that the tropical areas, in particular the continents, are unconstrained by the inverse system. The inverse system partly relies on the terrestrial reference fluxes and adjust the tropical source to match the surface

5 measurements over the tropics. If the tropical oceanic release is probably underestimated in the reference fluxes, its magnitude remains highly uncertain. Contrariwise, in the high-latitudes, independent measurements suggest that the inversion has rightly corrected an underestimation of the GPP in the ORCHIDEE land surface model. Concerning the COS anthropogenic sources, Japanese measurements suggest that these are underestimated in Eastern China. Thus, the large amount of oceanic source could be an upper limit to compensate for too low anthropogenic sources in the tropics.

Acknowledgements. This study was funded by the CO2 Human Emissions (CHE) project which received funding from the European Union's Horizon 2020 research and innovation program under grant agreement no. 776186. The authors kindly thank the scientists who provided the measurements used in this study. In particular, the MIPAS averaging kernels were provided by Michael Kiefer. The surface measurements from the NOAA network have been performed by scientists affiliated with NOAA (S. Montzka, C. Siso, B. Miller, F. Moore). The airborne measurements from HIPPO have been made with the help of E. Atlas at Univ of Miami (for the HIPPO campaign). D. Yakir facilitates the collection of flask samples at WIS. S. Hattori facilitates the collection of flask samples over Japan. The authors also thank the LMDz developers for maintaining the dynamism and creativity of this climate model.

Code and data availability. The COS data were processed at KIT-IMK with the IMK/IAA retrieval processor from http://www.imkasf.kit.edu/english/308. The LMDz model is available from http://web.lmd.jussieu.fr/trac under the CeCILL v2 Free Software License. The COS measurements at station GIF can be downloaded at https://mycore.core-cloud.net/index.php/s/XwULEXsgwFM1Tus/download 


\section{References}

Alemohammad, S. H., Fang, B., Konings, A. G., Aires, F., Green, J. K., Kolassa, J., Miralles, D., Prigent, C., and Gentine, P.: Water, Energy, and Carbon with Artificial Neural Networks (WECANN): a statistically based estimate of global surface turbulent fluxes and gross primary productivity using solar-induced fluorescence, Biogeosciences, 14, 4101-4124, https://doi.org/https://doi.org/10.5194/bg-14-4101-2017, https://bg.copernicus.org/articles/14/4101/2017/, 2017.

Anav, A., Friedlingstein, P., Beer, C., Ciais, P., Harper, A., Jones, C., Murray-Tortarolo, G., Papale, D., Parazoo, N. C., Peylin, P., Piao, S., Sitch, S., Viovy, N., Wiltshire, A., and Zhao, M.: Spatiotemporal patterns of terrestrial gross primary production: A review, Reviews of Geophysics, 53, 785-818, https://doi.org/https://doi.org/10.1002/2015RG000483, https://agupubs.onlinelibrary.wiley.com/doi/abs/10. 1002/2015RG000483,_eprint: https://agupubs.onlinelibrary.wiley.com/doi/pdf/10.1002/2015RG000483, 2015.

Aydin, M., Britten, G. L., Montzka, S. A., Buizert, C., Primeau, F., Petrenko, V., Battle, M. B., Nicewonger, M. R., Patterson, J., Hmiel, B., and Saltzman, E. S.: Anthropogenic Impacts on Atmospheric Carbonyl Sulfide Since the 19th Century Inferred From Polar Firn Air and Ice Core Measurements, Journal of Geophysical Research: Atmospheres, 125, e2020JD033 074, https://doi.org/https://doi.org/10.1029/2020JD033074, https://agupubs.onlinelibrary.wiley.com/doi/abs/10.1029/2020JD033074,_eprint: https://agupubs.onlinelibrary.wiley.com/doi/pdf/10.1029/2020JD033074, 2020.

Bacour, C., Maignan, F., Peylin, P., MacBean, N., Bastrikov, V., Joiner, J., Köhler, P., Guanter, L., and Frankenberg, C.: Differences Between OCO-2 and GOME-2 SIF Products From a Model-Data Fusion Perspective, Journal of Geophysical Research: Biogeosciences, 124, 3143-3157, https://doi.org/10.1029/2018JG004938, https://agupubs.onlinelibrary.wiley.com/doi/abs/10.1029/2018JG004938, _eprint: https://agupubs.onlinelibrary.wiley.com/doi/pdf/10.1029/2018JG004938, 2019.

Badgley, G., Anderegg, L. D. L., Berry, J. A., and Field, C. B.: Terrestrial gross primary production: Using NIRV to scale from site to globe, Global Change Biology, 25, 3731-3740, https://doi.org/https://doi.org/10.1111/gcb.14729, https://onlinelibrary.wiley.com/doi/abs/ 10.1111/gcb.14729, 2019.

Barnes, I., Becker, K. H., and Patroescu, I.: FTIR product study of the OH initiated oxidation of dimethyl sulphide: Observation of carbonyl sulphide and dimethyl sulphoxide, Atmospheric Environment, 30, 1805-1814, https://doi.org/10.1016/1352-2310(95)00389-4, http://www.sciencedirect.com/science/article/pii/1352231095003894, 1996.

Beer, C., Ciais, P., Reichstein, M., Baldocchi, D., Law, B. E., Papale, D., Soussana, J.-F., Ammann, C., Buchmann, N., Frank, D., Gianelle, D., Janssens, I. A., Knohl, A., Köstner, B., Moors, E., Roupsard, O., Verbeeck, H., Vesala, T., Williams, C. A., and Wohlfahrt, G.: Temporal and among-site variability of inherent water use efficiency at the ecosystem level, Global Biogeochemical Cycles, 23, https://doi.org/https://doi.org/10.1029/2008GB003233, https://agupubs.onlinelibrary.wiley.com/doi/abs/10.1029/2008GB003233, 2009.

Beer, C., Reichstein, M., Tomelleri, E., Ciais, P., Jung, M., Carvalhais, N., Rödenbeck, C., Arain, M. A., Baldocchi, D., Bonan, G. B., Bondeau, A., Cescatti, A., Lasslop, G., Lindroth, A., Lomas, M., Luyssaert, S., Margolis, H., Oleson, K. W., Roupsard, O., Veenendaal, E., Viovy, N., Williams, C., Woodward, F. I., and Papale, D.: Terrestrial gross carbon dioxide uptake: global distribution and covariation with climate, Science (New York, N.Y.), 329, 834-838, https://doi.org/10.1126/science.1184984, 2010.

Belviso, S., Nguyen, B. C., and Allard, P.: Estimate of carbonyl sulfide (OCS) volcanic source strength deduced from OCS/CO2 ratios in volcanic gases, Geophysical Research Letters, 13, 133-136, https://doi.org/https://doi.org/10.1029/GL013i002p00133, https://agupubs. onlinelibrary.wiley.com/doi/abs/10.1029/GL013i002p00133, 1986. 
Belviso, S., Masotti, I., Tagliabue, A., Bopp, L., Brockmann, P., Fichot, C., Caniaux, G., Prieur, L., Ras, J., Uitz, J., Loisel, H., Dessailly, D., Alvain, S., Kasamatsu, N., and Fukuchi, M.: DMS dynamics in the most oligotrophic subtropical zones of the global ocean, Biogeochemistry, 110, 215-241, https://doi.org/10.1007/s10533-011-9648-1, https://doi.org/10.1007/s10533-011-9648-1, 2012.

Belviso, S., Lebegue, B., Ramonet, M., Kazan, V., Pison, I., Berchet, A., Delmotte, M., Yver-Kwok, C., Montagne, D., and Ciais, P.: A topdown approach of sources and non-photosynthetic sinks of carbonyl sulfide from atmospheric measurements over multiple years in the Paris region (France), PLOS ONE, 15, e0228 419, https://doi.org/10.1371/journal.pone.0228419, https://journals.plos.org/plosone/article? id=10.1371/journal.pone.0228419, 2020.

Berchet, A., Sollum, E., Thompson, R. L., Pison, I., Thanwerdas, J., Broquet, G., Chevallier, F., Aalto, T., Bergamaschi, P., Brunner, D., Engelen, R., Fortems-Cheiney, A., Gerbig, C., Groot Zwaaftink, C., Haussaire, J.-M., Henne, S., Houweling, S., Karstens, U., Kutsch, W. L., Luijkx, I. T., Monteil, G., Palmer, P. I., van Peet, J. C. A., Peters, W., Peylin, P., Potier, E., Rödenbeck, C., Saunois, M., Scholze, M., Tsuruta, A., and Zhao, Y.: The Community Inversion Framework v1.0: a unified system for atmospheric inversion studies, Geoscientific Model Development Discussions, pp. 1-41, https://doi.org/https://doi.org/10.5194/gmd-2020-407, https://gmd.copernicus.org/preprints/ gmd-2020-407/, publisher: Copernicus GmbH, 2020.

Berndt, T., Scholz, W., Mentler, B., Fischer, L., Hoffmann, E. H., Tilgner, A., Hyttinen, N., Prisle, N. L., Hansel, A., and Herrmann, H.: Fast Peroxy Radical Isomerization and OH Recycling in the Reaction of OH Radicals with Dimethyl Sulfide, The Journal of Physical Chemistry Letters, 10, 6478-6483, https://doi.org/10.1021/acs.jpclett.9b02567, https://doi.org/10.1021/acs.jpclett.9b02567, publisher: American Chemical Society, 2019.

Berry, J., Wolf, A., Campbell, J. E., Baker, I., Blake, N., Blake, D., Denning, A. S., Kawa, S. R., Montzka, S. A., Seibt, U., Stimler, K., Yakir, D., and Zhu, Z.: A coupled model of the global cycles of carbonyl sulfide and CO2: A possible new window on the carbon cycle, Journal of Geophysical Research: Biogeosciences, 118, 842-852, https://doi.org/10.1002/jgrg.20068, https://agupubs.onlinelibrary.wiley. com/doi/abs/10.1002/jgrg.20068,_eprint: https://agupubs.onlinelibrary.wiley.com/doi/pdf/10.1002/jgrg.20068, $2013 \mathrm{a}$.

Berry, J., Wolf, A., Campbell, J. E., Baker, I., Blake, N., Blake, D., Denning, A. S., Kawa, S. R., Montzka, S. A., Seibt, U., Stimler, K., Yakir, D., and Zhu, Z.: A coupled model of the global cycles of carbonyl sulfide and CO2: A possible new window on the carbon cycle, Journal of Geophysical Research: Biogeosciences, 118, 842-852, https://doi.org/10.1002/jgrg.20068, https://agupubs.onlinelibrary.wiley. com/doi/abs/10.1002/jgrg.20068,_eprint: https://agupubs.onlinelibrary.wiley.com/doi/pdf/10.1002/jgrg.20068, 2013b.

Blake, N. J., Streets, D. G., Woo, J.-H., Simpson, I. J., Green, J., Meinardi, S., Kita, K., Atlas, E., Fuelberg, H. E., Sachse, G., Avery, M. A., Vay, S. A., Talbot, R. W., Dibb, J. E., Bandy, A. R., Thornton, D. C., Rowland, F. S., and Blake, D. R.: Carbonyl sulfide and carbon disulfide: Large-scale distributions over the western Pacific and emissions from Asia during TRACE-P, Journal of Geophysical Research: Atmospheres, 109, https://doi.org/https://doi.org/10.1029/2003JD004259, https://agupubs.onlinelibrary.wiley.com/doi/abs/10.1029/2003JD004259\%4010.1002/\%28ISSN\%292169-8996.TRACEP1, _eprint: https://agupubs.onlinelibrary.wiley.com/doi/pdf/10.1029/2003JD004259, 2004.

Blake, N. J., Campbell, J. E., Vay, S. A., Fuelberg, H. E., Huey, L. G., Sachse, G., Meinardi, S., Beyersdorf, A., Baker, A., Barletta, B., Midyett, J., Doezema, L., Kamboures, M., McAdams, J., Novak, B., Rowland, F. S., and Blake, D. R.: Carbonyl sulfide (OCS): Largescale distributions over North America during INTEX-NA and relationship to CO2, Journal of Geophysical Research: Atmospheres, 113, https://doi.org/https://doi.org/10.1029/2007JD009163, https://agupubs.onlinelibrary.wiley.com/doi/abs/10.1029/2007JD009163,_eprint: https://agupubs.onlinelibrary.wiley.com/doi/pdf/10.1029/2007JD009163, 2008.

Campbell, J. E., Carmichael, G. R., Chai, T., Mena-Carrasco, M., Tang, Y., Blake, D. R., Blake, N. J., Vay, S. A., Collatz, G. J., Baker, I., Berry, J. A., Montzka, S. A., Sweeney, C., Schnoor, J. L., and Stanier, C. O.: Photosynthetic Control of Atmospheric Carbonyl Sulfide 
During the Growing Season, Science, 322, 1085-1088, https://doi.org/10.1126/science.1164015, https://science.sciencemag.org/content/ 322/5904/1085, publisher: American Association for the Advancement of Science Section: Report, 2008.

Campbell, J. E., Berry, J. A., Seibt, U., Smith, S. J., Montzka, S. A., Launois, T., Belviso, S., Bopp, L., and Laine, M.: Large historical growth in global terrestrial gross primary production, Nature, 544, 84-87, https://doi.org/10.1038/nature22030, https://www.nature.com/articles/ nature22030, number: 7648 Publisher: Nature Publishing Group, 2017.

Chevallier, F.: Impact of correlated observation errors on inverted CO2 surface fluxes from OCO measurements, Geophysical Research Letters, 34, https://doi.org/https://doi.org/10.1029/2007GL030463, https://agupubs.onlinelibrary.wiley.com/doi/abs/10.1029/2007GL030463, 2007.

Chevallier, F.: On the statistical optimality of $\mathrm{CO}_{2}$ atmospheric inversions assimilating $\mathrm{CO}_{2}$ column retrievals, Atmospheric Chemistry and Physics, 15, 11 133-11 145, https://doi.org/10.5194/acp-15-11133-2015, https://acp.copernicus.org/articles/15/11133/2015/, publisher: Copernicus GmbH, 2015.

Chevallier, F., Engelen, R. J., and Peylin, P.: The contribution of AIRS data to the estimation of CO2 sources and sinks, Geophysical Research Letters, 32, L23 801, https://doi.org/10.1029/2005GL024229, http://onlinelibrary.wiley.com/doi/10.1029/2005GL024229/abstract, 2005.

Chevallier, F., Ciais, P., Conway, T. J., Aalto, T., Anderson, B. E., Bousquet, P., Brunke, E. G., Ciattaglia, L., Esaki, Y., Fröhlich, M., Gomez, A., Gomez-Pelaez, A. J., Haszpra, L., Krummel, P. B., Langenfelds, R. L., Leuenberger, M., Machida, T., Maignan, F., Matsueda, H., Morguí, J. A., Mukai, H., Nakazawa, T., Peylin, P., Ramonet, M., Rivier, L., Sawa, Y., Schmidt, M., Steele, L. P., Vay, S. A., Vermeulen, A. T., Wofsy, S., and Worthy, D.: CO2 surface fluxes at grid point scale estimated from a global 21 year reanalysis of atmospheric measurements, Journal of Geophysical Research: Atmospheres, 115, https://doi.org/10.1029/2010JD013887, https://agupubs.onlinelibrary.wiley. com/doi/abs/10.1029/2010JD013887,_eprint: https://agupubs.onlinelibrary.wiley.com/doi/pdf/10.1029/2010JD013887, 2010.

Chiodini, G., Cioni, R., Raco, B., and Scandiffio, G.: Carbonyl sulphide (cos) in geothermal fluids: an example from the Larderello field (Italy), Geothermics, 20, 319-327, https://doi.org/10.1016/0375-6505(91)90023-O, https://www.sciencedirect.com/science/article/ pii/0375650591900230, 1991.

Commane, R., Meredith, L. K., Baker, I. T., Berry, J. A., Munger, J. W., Montzka, S. A., Templer, P. H., Juice, S. M., Zahniser, M. S., and Wofsy, S. C.: Seasonal fluxes of carbonyl sulfide in a midlatitude forest, Proceedings of the National Academy of Sciences, 112 , 14 16214 167, https://doi.org/10.1073/pnas.1504131112, https://www.pnas.org/content/112/46/14162, publisher: National Academy of Sciences Section: Physical Sciences, 2015.

Denvil-Sommer, A., Gehlen, M., Vrac, M., and Mejia, C.: LSCE-FFNN-v1: a two-step neural network model for the reconstruction of surface ocean $\mathrm{pCO}_{2}$ over the global ocean, Geoscientific Model Development, 12, 2091-2105, https://doi.org/https://doi.org/10.5194/gmd-122091-2019, https://gmd.copernicus.org/articles/12/2091/2019/, 2019.

Du, Q., Zhang, C., Mu, Y., Cheng, Y., Zhang, Y., Liu, C., Song, M., Tian, D., Liu, P., Liu, J., Xue, C., and Ye, C.: An important missing source of atmospheric carbonyl sulfide: Domestic coal combustion, Geophysical Research Letters, 43, 8720-8727, https://doi.org/https://doi.org/10.1002/2016GL070075, https://agupubs.onlinelibrary.wiley.com/doi/abs/10.1002/2016GL070075,_eprint: https://agupubs.onlinelibrary.wiley.com/doi/pdf/10.1002/2016GL070075, 2016.

Fischer, H., Birk, M., Blom, C., Carli, B., Carlotti, M., von Clarmann, T., Delbouille, L., Dudhia, A., Ehhalt, D., Endemann, M., Flaud, J. M.,

Gessner, R., Kleinert, A., Koopman, R., Langen, J., López-Puertas, M., Mosner, P., Nett, H., Oelhaf, H., Perron, G., Remedios, J., Ridolfi, M., Stiller, G., and Zander, R.: MIPAS: an instrument for atmospheric and climate research, Atmospheric Chemistry and Physics, 8 , 2151-2188, https://doi.org/https://doi.org/10.5194/acp-8-2151-2008, https://acp.copernicus.org/articles/8/2151/2008/, publisher: Copernicus GmbH, 2008. 
Frankenberg, C., Fisher, J. B., Worden, J., Badgley, G., Saatchi, S. S., Lee, J.-E., Toon, G. C., Butz, A., Jung, M., Kuze, A., and Yokota, T.: New global observations of the terrestrial carbon cycle from GOSAT: Patterns of plant fluorescence with gross primary productivity, Geophysical Research Letters, 38, https://doi.org/https://doi.org/10.1029/2011GL048738, https://agupubs.onlinelibrary.wiley.com/doi/abs/10. 1029/2011GL048738,_eprint: https://agupubs.onlinelibrary.wiley.com/doi/pdf/10.1029/2011GL048738, 2011.

5 Friedlingstein, P., O’Sullivan, M., Jones, M. W., Andrew, R. M., Hauck, J., Olsen, A., Peters, G. P., Peters, W., Pongratz, J., Sitch, S., Le Quéré, C., Canadell, J. G., Ciais, P., Jackson, R. B., Alin, S., Aragão, L. E. O. C., Arneth, A., Arora, V., Bates, N. R., Becker, M., Benoit-Cattin, A., Bittig, H. C., Bopp, L., Bultan, S., Chandra, N., Chevallier, F., Chini, L. P., Evans, W., Florentie, L., Forster, P. M., Gasser, T., Gehlen, M., Gilfillan, D., Gkritzalis, T., Gregor, L., Gruber, N., Harris, I., Hartung, K., Haverd, V., Houghton, R. A., Ilyina, T., Jain, A. K., Joetzjer, E., Kadono, K., Kato, E., Kitidis, V., Korsbakken, J. I., Landschützer, P., Lefèvre, N., Lenton, A., Lienert, S., Liu, Z., Lombardozzi, D., Marland, G., Metzl, N., Munro, D. R., Nabel, J. E. M. S., Nakaoka, S.-I., Niwa, Y., O’Brien, K., Ono, T., Palmer, P. I., Pierrot, D., Poulter, B., Resplandy, L., Robertson, E., Rödenbeck, C., Schwinger, J., Séférian, R., Skjelvan, I., Smith, A. J. P., Sutton, A. J., Tanhua, T., Tans, P. P., Tian, H., Tilbrook, B., van der Werf, G., Vuichard, N., Walker, A. P., Wanninkhof, R., Watson, A. J., Willis, D., Wiltshire, A. J., Yuan, W., Yue, X., and Zaehle, S.: Global Carbon Budget 2020, Earth System Science Data, 12, 3269-3340, https://doi.org/https://doi.org/10.5194/essd-12-3269-2020, https://essd.copernicus.org/articles/12/3269/2020/, publisher: Copernicus GmbH, 2020.

Geels, C., Gloor, M., Ciais, P., Bousquet, P., Peylin, P., Vermeulen, A. T., Dargaville, R., Aalto, T., Brandt, J., Christensen, J. H., Frohn, L. M., Haszpra, L., Karstens, U., Rödenbeck, C., Ramonet, M., Carboni, G., and Santaguida, R.: Comparing atmospheric transport models for future regional inversions over Europe \&ndash; Part 1: mapping the atmospheric $\mathrm{CO}_{2}$ signals, Atmospheric Chemistry and Physics, 7 , 3461-3479, https://doi.org/https://doi.org/10.5194/acp-7-3461-2007, https://www.atmos-chem-phys.net/7/3461/2007/, publisher: Copernicus GmbH, 2007.

Glatthor, N., Höpfner, M., Baker, I. T., Berry, J., Campbell, J. E., Kawa, S. R., Krysztofiak, G., Leyser, A., Sinnhuber, B.-M., Stiller, G. P., Stinecipher, J., and Clarmann, T. v.: Tropical sources and sinks of carbonyl sulfide observed from space, Geophysical Research Letters, 42, 10,082-10,090, https://doi.org/10.1002/2015GL066293, https://agupubs.onlinelibrary.wiley.com/doi/abs/10.1002/ 2015GL066293,_eprint: https://agupubs.onlinelibrary.wiley.com/doi/pdf/10.1002/2015GL066293, 2015.

Glatthor, N., Höpfner, M., Leyser, A., Stiller, G. P., Clarmann, T. v., Grabowski, U., Kellmann, S., Linden, A., Sinnhuber, B.-M., Krysztofiak, G., and Walker, K. A.: Global carbonyl sulfide (OCS) measured by MIPAS/Envisat during 2002-2012, Atmospheric Chemistry and Physics, 17, 2631-2652, https://doi.org/https://doi.org/10.5194/acp-17-2631-2017, https://www.atmos-chem-phys.net/17/2631/2017/, publisher: Copernicus GmbH, 2017.

Gondwe, M., Krol, M., Gieskes, W., Klaassen, W., and Baar, H. d.: The contribution of ocean-leaving DMS to the global atmospheric burdens of DMS, MSA, SO2, and NSS SO4=, Global Biogeochemical Cycles, 17, https://doi.org/https://doi.org/10.1029/2002GB001937, https://agupubs.onlinelibrary.wiley.com/doi/abs/10.1029/2002GB001937, _eprint: https://agupubs.onlinelibrary.wiley.com/doi/pdf/10.1029/2002GB001937, 2003.

Guanter, L., Frankenberg, C., Dudhia, A., Lewis, P. E., Gómez-Dans, J., Kuze, A., Suto, H., and Grainger, R. G.: Retrieval and global assessment of terrestrial chlorophyll fluorescence from GOSAT space measurements, Remote Sensing of Environment, 121, 236-251, https://doi.org/10.1016/j.rse.2012.02.006, https://www.sciencedirect.com/science/article/pii/S0034425712000909, 2012.

Hattori, S., Kamezaki, K., and Yoshida, N.: Constraining the atmospheric OCS budget from sulfur isotopes, Proceedings of the National Academy of Sciences, 117, 20 447-20 452, https://doi.org/10.1073/pnas.2007260117, https://www.pnas.org/content/117/34/20447, publisher: National Academy of Sciences Section: Physical Sciences, 2020. 
Hauglustaine, D. A., Hourdin, F., Jourdain, L., Filiberti, M.-A., Walters, S., Lamarque, J.-F., and Holland, E. A.: Interactive chemistry in the Laboratoire de Météorologie Dynamique general circulation model: Description and background tropospheric chemistry evaluation, Journal of Geophysical Research: Atmospheres, 109, https://doi.org/https://doi.org/10.1029/2003JD003957, https://agupubs.onlinelibrary. wiley.com/doi/abs/10.1029/2003JD003957,_eprint: https://agupubs.onlinelibrary.wiley.com/doi/pdf/10.1029/2003JD003957, 2004.

Hilton, T. W., Whelan, M. E., Zumkehr, A., Kulkarni, S., Berry, J. A., Baker, I. T., Montzka, S. A., Sweeney, C., Miller, B. R., and Elliott Campbell, J.: Peak growing season gross uptake of carbon in North America is largest in the Midwest USA, Nature Climate Change, 7, 450-454, https://doi.org/10.1038/nclimate3272, https://www.nature.com/articles/nclimate3272, number: 6 Publisher: Nature Publishing Group, 2017.

Hourdin, F. and Armengaud, A.: The Use of Finite-Volume Methods for Atmospheric Advection of Trace Species. Part I: Test of Various Formulations in a General Circulation Model, Monthly Weather Review, 127, 822-837, https://doi.org/10.1175/15200493(1999)127<0822:TUOFVM>2.0.CO;2, https://journals.ametsoc.org/view/journals/mwre/127/5/1520-0493_1999_127_0822_ tuofvm_2.0.co_2.xml, publisher: American Meteorological Society Section: Monthly Weather Review, 1999.

Hourdin, F. and Talagrand, O.: Eulerian backtracking of atmospheric tracers. I: Adjoint derivation and parametrization of subgrid-scale transport, Quarterly Journal of the Royal Meteorological Society, 132, 567-583, https://doi.org/10.1256/qj.03.198.A, https://rmets. onlinelibrary.wiley.com/doi/abs/10.1256/qj.03.198.A,_eprint: https://rmets.onlinelibrary.wiley.com/doi/pdf/10.1256/qj.03.198.A, 2006.

Hourdin, F., Musat, I., Bony, S., Braconnot, P., Codron, F., Dufresne, J.-L., Fairhead, L., Filiberti, M.-A., Friedlingstein, P., Grandpeix, J.-Y., Krinner, G., LeVan, P., Li, Z.-X., and Lott, F.: The LMDZ4 general circulation model: climate performance and sensitivity to parametrized physics with emphasis on tropical convection, Climate Dynamics, 27, 787-813, https://doi.org/10.1007/s00382-006-0158-0, https://doi.org/10.1007/s00382-006-0158-0, 2006.

Hourdin, F., Rio, C., Grandpeix, J.-Y., Madeleine, J.-B., Cheruy, F., Rochetin, N., Jam, A., Musat, I., Idelkadi, A., Fairhead, L., Foujols, M.-A., Mellul, L., Traore, A.-K., Dufresne, J.-L., Boucher, O., Lefebvre, M.-P., Millour, E., Vignon, E., Jouhaud, J., Diallo, F. B., Lott, F., Gastineau, G., Caubel, A., Meurdesoif, Y., and Ghattas, J.: LMDZ6A: the atmospheric component of the IPSL climate model with improved and better tuned physics, Journal of Advances in Modeling Earth Systems, n/a, e2019MS001 892, https://doi.org/10.1029/2019MS001892, https://agupubs.onlinelibrary.wiley.com/doi/abs/10.1029/ 2019MS001892,_eprint: https://agupubs.onlinelibrary.wiley.com/doi/pdf/10.1029/2019MS001892, 2020.

Jasechko, S.: Global Isotope Hydrogeology-Review, Reviews of Geophysics, 57, 835-965, https://doi.org/https://doi.org/10.1029/2018RG000627, https://agupubs.onlinelibrary.wiley.com/doi/abs/10.1029/2018RG000627, 2019.

Joiner, J., Guanter, L., Lindstrot, R., Voigt, M., Vasilkov, A. P., Middleton, E. M., Huemmrich, K. F., Yoshida, Y., and Frankenberg, C.: Global monitoring of terrestrial chlorophyll fluorescence from moderate-spectral-resolution near-infrared satellite measurements: methodology, simulations, and application to GOME-2, Atmospheric Measurement Techniques, 6, 2803-2823, https://doi.org/10.5194/amt-6-28032013, https://amt.copernicus.org/articles/6/2803/2013/, publisher: Copernicus GmbH, 2013.

Joiner, J., Yoshida, Y., Guanter, L., and Middleton, E. M.: New methods for the retrieval of chlorophyll red fluorescence from hyperspectral satellite instruments: simulations and application to GOME-2 and SCIAMACHY, Atmospheric Measurement Techniques, 9, 3939-3967, https://doi.org/10.5194/amt-9-3939-2016, https://amt.copernicus.org/articles/9/3939/2016/, publisher: Copernicus GmbH, 2016.

Jones, M. W., Andrew, R. M., Peters, G. P., Janssens-Maenhout, G., De-Gol, A. J., Ciais, P., Patra, P. K., Chevallier, F., and Le Quéré, C.: Gridded fossil CO 2 emissions and related O 2 combustion consistent with national inventories 1959-2018, Scientific Data, 8, 2, https://doi.org/10.1038/s41597-020-00779-6, https://www.nature.com/articles/s41597-020-00779-6, 2021. 
Jung, M., Schwalm, C., Migliavacca, M., Walther, S., Camps-Valls, G., Koirala, S., Anthoni, P., Besnard, S., Bodesheim, P., Carvalhais, N., Chevallier, F., Gans, F., Goll, D. S., Haverd, V., Köhler, P., Ichii, K., Jain, A. K., Liu, J., Lombardozzi, D., Nabel, J. E. M. S., Nelson, J. A., O’Sullivan, M., Pallandt, M., Papale, D., Peters, W., Pongratz, J., Rödenbeck, C., Sitch, S., Tramontana, G., Walker, A., Weber, U., and Reichstein, M.: Scaling carbon fluxes from eddy covariance sites to globe: synthesis and evaluation of the FLUXCOM approach, Biogeosciences, 17, 1343-1365, https://doi.org/https://doi.org/10.5194/bg-17-1343-2020, https://bg.copernicus.org/articles/17/ 1343/2020/, publisher: Copernicus GmbH, 2020.

Kanda, K.-i., Tsuruta, H., and Minami, K.: Emission of dimethyl sulfide, carbonyl sulfide, and carbon bisulfide from paddy fields, Soil Science and Plant Nutrition, 38, 709-716, https://doi.org/10.1080/00380768.1992.10416701, https://doi.org/10.1080/00380768.1992.10416701, publisher: Taylor \& Francis _eprint: https://doi.org/10.1080/00380768.1992.10416701, 1992.

Kettle, A. J., Kuhn, U., Hobe, M. v., Kesselmeier, J., and Andreae, M. O.: Global budget of atmospheric carbonyl sulfide: Temporal and spatial variations of the dominant sources and sinks, Journal of Geophysical Research: Atmospheres, 107, ACH 25-1ACH 25-16, https://doi.org/10.1029/2002JD002187, https://agupubs.onlinelibrary.wiley.com/doi/abs/10.1029/2002JD002187, _eprint: https://agupubs.onlinelibrary.wiley.com/doi/pdf/10.1029/2002JD002187, 2002.

Khalil, M. A. K. and Rasmussen, R. A.: Global sources, lifetimes and mass balances of carbonyl sulfide (OCS) and carbon disulfide (CS2) in the earth's atmosphere, Atmospheric Environment (1967), 18, 1805-1813, https://doi.org/10.1016/0004-6981(84)90356-1, http://www. sciencedirect.com/science/article/pii/0004698184903561, 1984.

Khan, A., Razis, B., Gillespie, S., Percival, C., and Shallcross, D.: Global analysis of carbon disulfide $\left(\mathrm{CS}_{2}\right)$ using the 3-D chemistry transport model STOCHEM, AIMS Environmental Science, 4, 484, https://doi.org/10.3934/environsci.2017.3.484, https://www.aimspress.com/ article/10.3934/environsci.2017.3.484, company: Aims Press Distributor: Aims Press Institution: Aims Press Label: Aims Press Publisher: AIMS Press, 2017.

Kooijmans, L. M. J., Sun, W., Aalto, J., Erkkilä, K.-M., Maseyk, K., Seibt, U., Vesala, T., Mammarella, I., and Chen, H.: Influences of light and humidity on carbonyl sulfide-based estimates of photosynthesis, Proceedings of the National Academy of Sciences, 116, 2470-2475, https://doi.org/10.1073/pnas.1807600116, https://www.pnas.org/content/116/7/2470, publisher: National Academy of Sciences Section: Physical Sciences, 2019.

Krinner, G., Viovy, N., Noblet-Ducoudré, N. d., Ogée, J., Polcher, J., Friedlingstein, P., Ciais, P., Sitch, S., and Prentice, I. C.: A dynamic global vegetation model for studies of the coupled atmosphere-biosphere system, Global Biogeochemical Cycles, 19, https://doi.org/10.1029/2003GB002199, https://agupubs.onlinelibrary.wiley.com/doi/abs/10.1029/2003GB002199, _eprint: https://agupubs.onlinelibrary.wiley.com/doi/pdf/10.1029/2003GB002199, 2005.

Krysztofiak, G., Té, Y. V., Catoire, V., Berthet, G., Toon, G. C., Jégou, F., Jeseck, P., and Robert, C.: Carbonyl Sulphide (OCS) Variability with Latitude in the Atmosphere, Atmosphere-Ocean, 53, 89-101, https://doi.org/10.1080/07055900.2013.876609, https://doi.org/10. 1080/07055900.2013.876609, 2015.

Kuai, L., Worden, J. R., Campbell, J. E., Kulawik, S. S., Li, K.-F., Lee, M., Weidner, R. J., Montzka, S. A., Moore, F. L., Berry, J. A., Baker, I., Denning, A. S., Bian, H., Bowman, K. W., Liu, J., and Yung, Y. L.: Estimate of carbonyl sulfide tropical oceanic surface fluxes using Aura Tropospheric Emission Spectrometer observations, Journal of Geophysical Research: Atmospheres, 120, 11,012-11,023, https://doi.org/10.1002/2015JD023493, https://agupubs.onlinelibrary.wiley.com/doi/abs/10.1002/2015JD023493, _eprint: https://agupubs.onlinelibrary.wiley.com/doi/pdf/10.1002/2015JD023493, 2015a.

Kuai, L., Worden, J. R., Campbell, J. E., Kulawik, S. S., Li, K.-F., Lee, M., Weidner, R. J., Montzka, S. A., Moore, F. L., Berry, J. A., Baker, I., Denning, A. S., Bian, H., Bowman, K. W., Liu, J., and Yung, Y. L.: Estimate of carbonyl sulfide tropical 
oceanic surface fluxes using Aura Tropospheric Emission Spectrometer observations, Journal of Geophysical Research: Atmospheres, 120, 11,012-11,023, https://doi.org/10.1002/2015JD023493, https://agupubs.onlinelibrary.wiley.com/doi/abs/10.1002/2015JD023493, _eprint: https://agupubs.onlinelibrary.wiley.com/doi/pdf/10.1002/2015JD023493, 2015b.

Kuhn, U. and Kesselmeier, J.: Environmental variables controlling the uptake of carbonyl sulfide by lichens, Journal of Geophysical Research: Atmospheres, 105, 26 783-26 792, https://doi.org/https://doi.org/10.1029/2000JD900436, https://agupubs.onlinelibrary.wiley. com/doi/abs/10.1029/2000JD900436, _eprint: https://agupubs.onlinelibrary.wiley.com/doi/pdf/10.1029/2000JD900436, 2000.

Kuppel, S., Peylin, P., Chevallier, F., Bacour, C., Maignan, F., and Richardson, A. D.: Constraining a global ecosystem model with multi-site eddy-covariance data, Biogeosciences, 9, 3757-3776, https://doi.org/https://doi.org/10.5194/bg-9-3757-2012, https://bg.copernicus.org/ articles/9/3757/2012/, 2012.

Lana, A., Bell, T. G., Simó, R., Vallina, S. M., Ballabrera-Poy, J., Kettle, A. J., Dachs, J., Bopp, L., Saltzman, E. S., Stefels, J., Johnson, J. E., and Liss, P. S.: An updated climatology of surface dimethlysulfide concentrations and emission fluxes in the global ocean, Global Biogeochemical Cycles, 25, https://doi.org/https://doi.org/10.1029/2010GB003850, https://agupubs.onlinelibrary.wiley.com/doi/abs/10.1029/ 2010GB003850,_eprint: https://agupubs.onlinelibrary.wiley.com/doi/pdf/10.1029/2010GB003850, 2011.

Launois, T., Belviso, S., Bopp, L., Fichot, C. G., and Peylin, P.: A new model for the global biogeochemical cycle of carbonyl sulfide \&ndash;

Part 1: Assessment of direct marine emissions with an oceanic general circulation and biogeochemistry model, Atmospheric Chemistry and Physics, 15, 2295-2312, https://doi.org/https://doi.org/10.5194/acp-15-2295-2015, https://www.atmos-chem-phys.net/15/2295/2015/, publisher: Copernicus GmbH, 2015a.

Launois, T., Peylin, P., Belviso, S., and Poulter, B.: A new model of the global biogeochemical cycle of carbonyl sulfide - Part 2: Use of carbonyl sulfide to constrain gross primary productivity in current vegetation models, Atmospheric Chemistry and Physics, 15, 92859312, https://doi.org/https://doi.org/10.5194/acp-15-9285-2015, https://www.atmos-chem-phys.net/15/9285/2015/, publisher: Copernicus $\mathrm{GmbH}, 2015 \mathrm{~b}$.

Lennartz, S. T., Marandino, C. A., Hobe, M. v., Cortes, P., Quack, B., Simo, R., Booge, D., Pozzer, A., Steinhoff, T., Arevalo-Martinez, D. L., Kloss, C., Bracher, A., Röttgers, R., Atlas, E., and Krüger, K.: Direct oceanic emissions unlikely to account for the missing source of atmospheric carbonyl sulfide, Atmospheric Chemistry and Physics, 17, 385-402, https://doi.org/https://doi.org/10.5194/acp-17-3852017, https://www.atmos-chem-phys.net/17/385/2017/, publisher: Copernicus GmbH, 2017.

Lennartz, S. T., von Hobe, M., Booge, D., Bittig, H. C., Fischer, T., Gonçalves-Araujo, R., Ksionzek, K. B., Koch, B. P., Bracher, A., Röttgers, R., Quack, B., and Marandino, C. A.: The influence of dissolved organic matter on the marine production of carbonyl sulfide (OCS) and carbon disulfide $\left(\mathrm{CS}_{2}\right)$ in the Peruvian upwelling, Ocean Science, 15, 1071-1090, https://doi.org/https://doi.org/10.5194/os-15-1071-2019, https://os.copernicus.org/articles/15/1071/2019/, 2019.

Lennartz, S. T., Gauss, M., von Hobe, M., and Marandino, C. A.: Monthly resolved modelled oceanic emissions of carbonyl sulfide and carbon disulfide for the period 2000\&ndash;2019, Earth System Science Data Discussions, pp. 1-27, https://doi.org/https://doi.org/10.5194/essd2020-389, https://essd.copernicus.org/preprints/essd-2020-389/, publisher: Copernicus GmbH, 2020a.

Lennartz, S. T., Marandino, C. A., Hobe, M. v., Andreae, M. O., Aranami, K., Atlas, E., Berkelhammer, M., Bingemer, H., Booge, D., Cutter, G., Cortes, P., Kremser, S., Law, C. S., Marriner, A., Simó, R., Quack, B., Uher, G., Xie, H., and Xu, X.: Marine carbonyl sulfide (OCS) and carbon disulfide $\left(\mathrm{CS}_{2}\right)$ : a compilation of measurements in seawater and the marine boundary layer, Earth System Science Data, 12, 591-609, https://doi.org/https://doi.org/10.5194/essd-12-591-2020, https://www.earth-syst-sci-data.net/12/591/2020/, publisher: Copernicus GmbH, 2020b. 
Li, X., Xiao, J., and He, B.: Chlorophyll fluorescence observed by OCO-2 is strongly related to gross primary productivity estimated from flux towers in temperate forests, Remote Sensing of Environment, 204, 659-671, https://doi.org/10.1016/j.rse.2017.09.034, http://www. sciencedirect.com/science/article/pii/S0034425717304467, 2018.

Locatelli, R., Bousquet, P., Hourdin, F., Saunois, M., Cozic, A., Couvreux, F., Grandpeix, J.-Y., Lefebvre, M.-P., Rio, C., Bergamaschi, P., Chambers, S. D., Karstens, U., Kazan, V., van der Laan, S., Meijer, H. a. J., Moncrieff, J., Ramonet, M., Scheeren, H. A., Schlosser, C., Schmidt, M., Vermeulen, A., and Williams, A. G.: Atmospheric transport and chemistry of trace gases in LMDz5B: evaluation and implications for inverse modelling, Geoscientific Model Development, 8, 129-150, https://doi.org/https://doi.org/10.5194/gmd-8-1292015, https://www.geosci-model-dev.net/8/129/2015/, publisher: Copernicus GmbH, 2015.

Ma, J., Kooijmans, L. M. J., Cho, A., Montzka, S. A., Glatthor, N., Worden, J. R., Kuai, L., Atlas, E. L., and Krol, M. C.: Inverse modelling of carbonyl sulfide: implementation, evaluation and implications for the global budget, Atmospheric Chemistry and Physics, 21, 3507-3529, https://doi.org/10.5194/acp-21-3507-2021, https://acp.copernicus.org/articles/21/3507/2021/, publisher: Copernicus GmbH, 2021.

Maignan, F., Abadie, C., Remaud, M., Kooiijmans, L. M. J., Kohonen, K.-M., Commane, R., Wehr, R., Campbell, J. E., Belviso, S., Montzka, S. A., Raoult, N., Seibt, U., Shiga, Y. P., Vuichard, N., Whelan, M. E., and Peylin, P.: Carbonyl Sulfide: Comparing a Mechanistic Representation of the Vegetation Uptake in a Land Surface Model and the Leaf Relative Uptake Approach, Biogeosciences Discussions, pp. 141, https://doi.org/https://doi.org/10.5194/bg-2020-381, https://bg.copernicus.org/preprints/bg-2020-381/, publisher: Copernicus GmbH, 2020.

Meredith, L. K., Boye, K., Youngerman, C., Whelan, M., Ogée, J., Sauze, J., and Wingate, L.: Coupled Biological and Abiotic Mechanisms Driving Carbonyl Sulfide Production in Soils, Soil Systems, 2, 37, https://doi.org/10.3390/soilsystems2030037, https://www.mdpi.com/ 2571-8789/2/3/37, number: 3 Publisher: Multidisciplinary Digital Publishing Institute, 2018.

Minami, K., Kanda, K.-I., and Tsuruta, H.: Emission of Biogenic Sulfur Gases from Rice Paddies in Japan, in: Biogeochemistry of Global Change: Radiatively Active Trace Gases Selected Papers from the Tenth International Symposium on Environmental Biogeochemistry, San Francisco, August 19-24, 1991, edited by Oremland, R. S., pp. 405-418, Springer US, Boston, MA, https://doi.org/10.1007/978-14615-2812-8_22, https://doi.org/10.1007/978-1-4615-2812-8_22, 1993.

Montzka, S. A., Calvert, P., Hall, B. D., Elkins, J. W., Conway, T. J., Tans, P. P., and Sweeney, C.: On the global distribution, seasonality, and budget of atmospheric carbonyl sulfide (COS) and some similarities to CO2, Journal of Geophysical Research: Atmospheres, 112, https://doi.org/10.1029/2006JD007665, https://agupubs.onlinelibrary.wiley.com/doi/abs/10.1029/2006JD007665, _eprint: https://agupubs.onlinelibrary.wiley.com/doi/pdf/10.1029/2006JD007665, 2007.

Notsu, K. and Mori, T.: Chemical monitoring of volcanic gas using remote FT-IR spectroscopy at several active volcanoes in Japan, Applied Geochemistry, 25, 505-512, https://doi.org/10.1016/j.apgeochem.2010.01.008, https://www.sciencedirect.com/science/article/pii/ S0883292710000272, 2010.

Ogée, J., Sauze, J., Kesselmeier, J., Genty, B., Van Diest, H., Launois, T., and Wingate, L.: A new mechanistic framework to predict OCS fluxes from soils, Biogeosciences, 13, 2221-2240, https://doi.org/https://doi.org/10.5194/bg-13-2221-2016, https://www.biogeosciences. net/13/2221/2016/bg-13-2221-2016.html, publisher: Copernicus GmbH, 2016.

Peylin, P., Bacour, C., MacBean, N., Leonard, S., Rayner, P., Kuppel, S., Koffi, E., Kane, A., Maignan, F., Chevallier, F., Ciais, P., and Prunet, P.: A new stepwise carbon cycle data assimilation system using multiple data streams to constrain the simulated land surface carbon cycle, Geoscientific Model Development, 9, 3321-3346, https://doi.org/https://doi.org/10.5194/gmd-9-3321-2016, https://www. geosci-model-dev.net/9/3321/2016/, 2016. 
Poulter, B., MacBean, N., Hartley, A., Khlystova, I., Arino, O., Betts, R., Bontemps, S., Boettcher, M., Brockmann, C., Defourny, P., Hagemann, S., Herold, M., Kirches, G., Lamarche, C., Lederer, D., Ottlé, C., Peters, M., and Peylin, P.: Plant functional type classification for earth system models: results from the European Space Agency's Land Cover Climate Change Initiative, Geoscientific Model Development, 8, 2315-2328, https://doi.org/https://doi.org/10.5194/gmd-8-2315-2015, https://www.geosci-model-dev.net/8/2315/2015/ gmd-8-2315-2015.html, publisher: Copernicus GmbH, 2015.

Protoschill-Krebs, G., Wilhelm, C., and Kesselmeier, J.: Consumption of carbonyl sulphide (COS) by higher plant carbonic anhydrase (CA), Atmospheric Environment, 30, 3151-3156, https://doi.org/10.1016/1352-2310(96)00026-X, http://www.sciencedirect.com/science/ article/pii/135223109600026X, 1996.

Rastogi, B., Berkelhammer, M., Wharton, S., Whelan, M. E., Itter, M. S., Leen, J. B., Gupta, M. X., Noone, D., and Still, C. J.: Large Uptake of Atmospheric OCS Observed at a Moist Old Growth Forest: Controls and Implications for Carbon Cycle Applications, Journal of Geophysical Research: Biogeosciences, 123, 3424-3438, https://doi.org/https://doi.org/10.1029/2018JG004430, https: //agupubs.onlinelibrary.wiley.com/doi/abs/10.1029/2018JG004430, 2018.

Remaud, M., Chevallier, F., Cozic, A., Lin, X., and Bousquet, P.: On the impact of recent developments of the LMDz atmospheric general circulation model on the simulation of $\mathrm{CO}_{2}$ transport, Geoscientific Model Development, 11, 44894513, https://doi.org/https://doi.org/10.5194/gmd-11-4489-2018, https://www.geosci-model-dev.net/11/4489/2018/, publisher: Copernicus GmbH, 2018.

Riley, W. J., Randerson, J. T., Foster, P. N., and Lueker, T. J.: Influence of terrestrial ecosystems and topography on coastal CO2 measurements: A case study at Trinidad Head, California, Journal of Geophysical Research: Biogeosciences, 110, https://doi.org/https://doi.org/10.1029/2004JG000007, https://agupubs.onlinelibrary.wiley.com/doi/abs/10.1029/2004JG000007, _eprint: https://agupubs.onlinelibrary.wiley.com/doi/pdf/10.1029/2004JG000007, 2005.

Ryu, Y., Baldocchi, D. D., Kobayashi, H., Ingen, C. v., Li, J., Black, T. A., Beringer, J., Gorsel, E. v., Knohl, A., Law, B. E., and Roupsard, O.: Integration of MODIS land and atmosphere products with a coupled-process model to estimate gross primary productivity and evapotranspiration from $1 \mathrm{~km}$ to global scales, Global Biogeochemical Cycles, 25, https://doi.org/https://doi.org/10.1029/2011GB004053, https://agupubs.onlinelibrary.wiley.com/doi/abs/10.1029/2011GB004053, 2011.

Sandoval-Soto, L., Stanimirov, M., Hobe, M. v., Schmitt, V., Valdes, J., Wild, A., and Kesselmeier, J.: Global uptake of carbonyl sulfide (COS) by terrestrial vegetation: Estimates corrected by deposition velocities normalized to the uptake of carbon dioxide $\left(\mathrm{CO}_{2}\right)$, Biogeosciences, 2, 125-132, https://doi.org/https://doi.org/10.5194/bg-2-125-2005, https://www.biogeosciences.net/2/125/2005/, publisher: Copernicus GmbH, 2005.

Sawyer, G. M., Carn, S. A., Tsanev, V. I., Oppenheimer, C., and Burton, M.: Investigation into magma degassing at Nyiragongo volcano, Democratic Republic of the Congo, Geochemistry, Geophysics, Geosystems, 9, https://doi.org/https://doi.org/10.1029/2007GC001829, https://agupubs.onlinelibrary.wiley.com/doi/abs/10.1029/2007GC001829, _eprint: https://agupubs.onlinelibrary.wiley.com/doi/pdf/10.1029/2007GC001829, 2008.

Seibt, U., Kesselmeier, J., Sandoval-Soto, L., Kuhn, U., and Berry, J. A.: A kinetic analysis of leaf uptake of COS and its relation to transpiration, photosynthesis and carbon isotope fractionation, Biogeosciences, 7, 333-341, https://doi.org/https://doi.org/10.5194/bg-7333-2010, https://www.biogeosciences.net/7/333/2010/bg-7-333-2010.html, publisher: Copernicus GmbH, 2010.

Serio, C., Masiello, G., Mastro, P., Cersosimo, A., Pasquariello, P., and Venafra, S.: Simultaneous retrieval of OCS, and CO2 from the IASI shortwave spectral band: assessment of the accuracy of the retrieval products and validation with in situ observations., in: Remote Sensing of Clouds and the Atmosphere XXV, vol. 11531, p. 1153107, International Society for Optics 
and Photonics, https://doi.org/10.1117/12.2573351, https://www.spiedigitallibrary.org/conference-proceedings-of-spie/11531/1153107/ Simultaneous-retrieval-of-OCS-and-CO2-from-the-IASI-shortwave/10.1117/12.2573351.short, 2020.

Stimler, K., Montzka, S. A., Berry, J. A., Rudich, Y., and Yakir, D.: Relationships between carbonyl sulfide (COS) and CO2 during leaf gas exchange, New Phytologist, 186, 869-878, https://doi.org/10.1111/j.1469-8137.2010.03218.x, https://nph.onlinelibrary.wiley.com/doi/abs/ 10.1111/j.1469-8137.2010.03218.x,_eprint: https://nph.onlinelibrary.wiley.com/doi/pdf/10.1111/j.1469-8137.2010.03218.x, 2010.

Stinecipher, J. R., Cameron-Smith, P. J., Blake, N. J., Kuai, L., Lejeune, B., Mahieu, E., Simpson, I. J., and Campbell, J. E.: Biomass Burning Unlikely to Account for Missing Source of Carbonyl Sulfide, Geophysical Research Letters, 46, 14912-14 920, https://doi.org/10.1029/2019GL085567, https://agupubs.onlinelibrary.wiley.com/doi/abs/10.1029/2019GL085567, _eprint: https://agupubs.onlinelibrary.wiley.com/doi/pdf/10.1029/2019GL085567, 2019.

Stocker, B. D., Zscheischler, J., Keenan, T. F., Prentice, I. C., Seneviratne, S. I., and Peñuelas, J.: Drought impacts on terrestrial primary production underestimated by satellite monitoring, Nature Geoscience, 12, 264-270, https://doi.org/10.1038/s41561-019-0318-6, https: //www.nature.com/articles/s41561-019-0318-6, 2019.

Sun, Y., Frankenberg, C., Jung, M., Joiner, J., Guanter, L., Köhler, P., and Magney, T.: Overview of Solar-Induced chlorophyll Fluorescence (SIF) from the Orbiting Carbon Observatory-2: Retrieval, cross-mission comparison, and global monitoring for GPP, Remote Sensing of Environment, 209, 808-823, https://doi.org/10.1016/j.rse.2018.02.016, https://www.sciencedirect.com/science/article/ pii/S0034425718300221, 2018.

Suntharalingam, P., Kettle, A. J., Montzka, S. M., and Jacob, D. J.: Global 3-D model analysis of the seasonal cycle of atmospheric carbonyl sulfide: Implications for terrestrial vegetation uptake, Geophysical Research Letters, 35, https://doi.org/10.1029/2008GL034332, ｈttps://agupubs.onlinelibrary.wiley.com/doi/abs/10.1029/2008GL034332, _eprint: https://agupubs.onlinelibrary.wiley.com/doi/pdf/10.1029/2008GL034332, 2008.

Sweeney, C., Karion, A., Wolter, S., Newberger, T., Guenther, D., Higgs, J. A., Andrews, A. E., Lang, P. M., Neff, D., Dlugokencky, E., Miller, J. B., Montzka, S. A., Miller, B. R., Masarie, K. A., Biraud, S. C., Novelli, P. C., Crotwell, M., Crotwell, A. M., Thoning, K., and Tans, P. P.: Seasonal climatology of CO2 across North America from aircraft measurements in the NOAA/ESRL Global Greenhouse Gas Reference Network, Journal of Geophysical Research: Atmospheres, 120, 5155-5190, https://doi.org/10.1002/2014JD022591, http: //onlinelibrary.wiley.com/doi/10.1002/2014JD022591/full, 2015.

Symonds, R. B., Reed, M. H., and Rose, W. I.: Origin, speciation, and fluxes of trace-element gases at Augustine volcano, Alaska: Insights into magma degassing and fumarolic processes, Geochimica et Cosmochimica Acta, 56, 633-657, https://doi.org/10.1016/00167037(92)90087-Y, https://www.sciencedirect.com/science/article/pii/001670379290087Y, 1992.

Tarantola, A.: Inverse problems theory, Methods for Data Fitting and Model Parameter Estimation, Elsevier, Southampton, 1989.

Thoning, K. W., Tans, P. P., and Komhyr, W. D.: Atmospheric carbon dioxide at Mauna Loa Observatory: 2. Analysis of the NOAA GMCC data, 1974-1985, Journal of Geophysical Research: Atmospheres, 94, 8549-8565, https://doi.org/10.1029/JD094iD06p08549, https://agupubs.onlinelibrary.wiley.com/doi/abs/10.1029/JD094iD06p08549,__eprint: https://agupubs.onlinelibrary.wiley.com/doi/pdf/10.1029/JD094iD06p08549, 1989.

Van Leer, B.: Towards the ultimate conservative difference scheme. IV. A new approach to numerical convection, Journal of

Computational Physics, 23, 276-299, https://doi.org/10.1016/0021-9991(77)90095-X, http://www.sciencedirect.com/science/article/pii/ $002199917790095 X, 1977$.

Veres, P. R., Neuman, J. A., Bertram, T. H., Assaf, E., Wolfe, G. M., Williamson, C. J., Weinzierl, B., Tilmes, S., Thompson, C. R., Thames, A. B., Schroder, J. C., Saiz-Lopez, A., Rollins, A. W., Roberts, J. M., Price, D., Peischl, J., Nault, B. A., Møller, K. H., Miller, 
D. O., Meinardi, S., Li, Q., Lamarque, J.-F., Kupc, A., Kjaergaard, H. G., Kinnison, D., Jimenez, J. L., Jernigan, C. M., Hornbrook, R. S., Hills, A., Dollner, M., Day, D. A., Cuevas, C. A., Campuzano-Jost, P., Burkholder, J., Bui, T. P., Brune, W. H., Brown, S. S., Brock, C. A., Bourgeois, I., Blake, D. R., Apel, E. C., and Ryerson, T. B.: Global airborne sampling reveals a previously unobserved dimethyl sulfide oxidation mechanism in the marine atmosphere, Proceedings of the National Academy of Sciences, 117, 4505-4510, https://doi.org/10.1073/pnas.1919344117, https://www.pnas.org/content/117/9/4505, publisher: National Academy of Sciences Section: Physical Sciences, 2020.

Vincent, R. A. and Dudhia, A.: Fast retrievals of tropospheric carbonyl sulfide with IASI, Atmospheric Chemistry and Physics, 17, 29813000, https://doi.org/https://doi.org/10.5194/acp-17-2981-2017, https://acp.copernicus.org/articles/17/2981/2017/, 2017.

Wang, Y., Deutscher, N. M., Palm, M., Warneke, T., Notholt, J., Baker, I., Berry, J., Suntharalingam, P., Jones, N., Mahieu, E., Lejeune, B.,

Hannigan, J., Conway, S., Mendonca, J., Strong, K., Campbell, J. E., Wolf, A., and Kremser, S.: Towards understanding the variability in biospheric $\mathrm{CO}_{2}$ fluxes: using FTIR spectrometry and a chemical transport model to investigate the sources and sinks of carbonyl sulfide and its link to $\mathrm{CO}_{2}$, Atmospheric Chemistry and Physics, 16, 2123-2138, https://doi.org/https://doi.org/10.5194/acp-16-21232016, https://acp.copernicus.org/articles/16/2123/2016/, publisher: Copernicus GmbH, 2016.

Watts, S. F.: The mass budgets of carbonyl sulfide, dimethyl sulfide, carbon disulfide and hydrogen sulfide, Atmospheric Environment,

34, 761-779, https://doi.org/10.1016/S1352-2310(99)00342-8, https://www.sciencedirect.com/science/article/pii/S1352231099003428, 2000.

Welp, L. R., Keeling, R. F., Meijer, H. A. J., Bollenbacher, A. F., Piper, S. C., Yoshimura, K., Francey, R. J., Allison, C. E., and Wahlen, M.: Interannual variability in the oxygen isotopes of atmospheric CO 2 driven by El Niño, Nature, 477, 579-582, https://doi.org/10.1038/nature10421, https://www.nature.com/articles/nature10421, 2011.

Whelan, M. E., Min, D.-H., and Rhew, R. C.: Salt marsh vegetation as a carbonyl sulfide (COS) source to the atmosphere, Atmospheric Environment, 73, 131-137, https://doi.org/10.1016/j.atmosenv.2013.02.048, http://www.sciencedirect.com/science/article/pii/ S135223101300160X, 2013.

Whelan, M. E., Hilton, T. W., Berry, J. A., Berkelhammer, M., Desai, A. R., and Campbell, J. E.: Carbonyl sulfide exchange in soils for better estimates of ecosystem carbon uptake, Atmospheric Chemistry and Physics, 16, 3711-3726, https://doi.org/https://doi.org/10.5194/acp16-3711-2016, https://www.atmos-chem-phys.net/16/3711/2016/acp-16-3711-2016.html, publisher: Copernicus GmbH, 2016.

Whelan, M. E., Lennartz, S. T., Gimeno, T. E., Wehr, R., Wohlfahrt, G., Wang, Y., Kooijmans, L. M. J., Hilton, T. W., Belviso, S., Peylin, P., Commane, R., Sun, W., Chen, H., Kuai, L., Mammarella, I., Maseyk, K., Berkelhammer, M., Li, K.-F., Yakir, D., Zumkehr, A., Katayama, Y., Ogée, J., Spielmann, F. M., Kitz, F., Rastogi, B., Kesselmeier, J., Marshall, J., Erkkilä, K.-M., Wingate, L., Meredith, L. K., He, W., Bunk, R., Launois, T., Vesala, T., Schmidt, J. A., Fichot, C. G., Seibt, U., Saleska, S., Saltzman, E. S., Montzka, S. A., Berry, J. A., and Campbell, J. E.: Reviews and syntheses: Carbonyl sulfide as a multi-scale tracer for carbon and water cycles, Biogeosciences, 15 , 3625-3657, https://doi.org/https://doi.org/10.5194/bg-15-3625-2018, https://www.biogeosciences.net/15/3625/2018/, publisher: Copernicus GmbH, 2018.

Wofsy, S. C.: HIAPER Pole-to-Pole Observations (HIPPO): fine-grained, global-scale measurements of climatically important atmospheric gases and aerosols, Philosophical Transactions of the Royal Society A: Mathematical, Physical and Engineering Sciences, 369, 20732086, https://doi.org/10.1098/rsta.2010.0313, https://royalsocietypublishing.org/doi/full/10.1098/rsta.2010.0313, publisher: Royal Society, 2011.

Yang, X., Tang, J., Mustard, J. F., Lee, J.-E., Rossini, M., Joiner, J., Munger, J. W., Kornfeld, A., and Richardson, A. D.: Solar-induced chlorophyll fluorescence that correlates with canopy photosynthesis on diurnal and seasonal scales in a temperate deciduous forest, Geo- 
physical Research Letters, 42, 2977-2987, https://doi.org/10.1002/2015GL063201, https://agupubs.onlinelibrary.wiley.com/doi/abs/10. 1002/2015GL063201,_eprint: https://agupubs.onlinelibrary.wiley.com/doi/pdf/10.1002/2015GL063201, 2015.

Yi, Z., Wang, X., Sheng, G., and Fu, J.: Exchange of carbonyl sulfide (OCS) and dimethyl sulfide (DMS) between rice paddy fields and the atmosphere in subtropical China, Agriculture, Ecosystems \& Environment, 123, 116-124, https://doi.org/10.1016/j.agee.2007.05.011, https://www.sciencedirect.com/science/article/pii/S0167880907001661, 2008.

Zhang, Y., Guanter, L., Berry, J. A., van der Tol, C., Yang, X., Tang, J., and Zhang, F.: Model-based analysis of the relationship between sun-induced chlorophyll fluorescence and gross primary production for remote sensing applications, Remote Sensing of Environment, 187, 145-155, https://doi.org/10.1016/j.rse.2016.10.016, https://www.sciencedirect.com/science/article/pii/S0034425716303893, 2016.

Zhao, Y., Saunois, M., Bousquet, P., Lin, X., Berchet, A., Hegglin, M. I., Canadell, J. G., Jackson, R. B., Deushi, M., Jöckel, P., Kinnison, D., Kirner, O., Strode, S., Tilmes, S., Dlugokencky, E. J., and Zheng, B.: On the role of trend and variability in the hydroxyl radical (OH) in the global methane budget, Atmospheric Chemistry and Physics, 20, 13 011-13 022, https://doi.org/https://doi.org/10.5194/acp-20-130112020, https://acp.copernicus.org/articles/20/13011/2020/, 2020a.

Zhao, Y., Saunois, M., Bousquet, P., Lin, X., Berchet, A., Hegglin, M. I., Canadell, J. G., Jackson, R. B., Dlugokencky, E. J., Langenfelds, R. L., Ramonet, M., Worthy, D., and Zheng, B.: Influences of hydroxyl radicals (OH) on top-down estimates of the global and regional methane budgets, Atmospheric Chemistry and Physics, 20, 9525-9546, https://doi.org/https://doi.org/10.5194/acp-20-9525-2020, https: //acp.copernicus.org/articles/20/9525/2020/, 2020b.

Zumkehr, A., Hilton, T. W., Whelan, M., Smith, S., and Campbell, J. E.: Gridded anthropogenic emissions inventory and atmospheric transport of carbonyl sulfide in the U.S., Journal of Geophysical Research: Atmospheres, 122, 21692178, https://doi.org/10.1002/2016JD025550, https://agupubs.onlinelibrary.wiley.com/doi/abs/10.1002/2016JD025550, _eprint: https://agupubs.onlinelibrary.wiley.com/doi/pdf/10.1002/2016JD025550, 2017.

Zumkehr, A., Hilton, T. W., Whelan, M., Smith, S., Kuai, L., Worden, J., and Campbell, J. E.: Global gridded anthropogenic emissions inventory of carbonyl sulfide, Atmospheric Environment, 183, 11-19, https://doi.org/10.1016/j.atmosenv.2018.03.063, http://www. sciencedirect.com/science/article/pii/S1352231018302255, 2018. 